\title{
BALB/c mice immunized with a combination of virus-like particles incorporating Kaposi sarcoma-associated herpesvirus (KSHV) envelope glycoproteins gpK8.1, gB, and $\mathrm{gH} / \mathrm{gL}$ induced comparable serum neutralizing antibody activity to UV-inactivated KSHV
}

\author{
Anne K. Barasa1,3, Peng Ye ${ }^{1}$, Meredith Phelps ${ }^{2}$, Ganapathiram T. Arivudainambi², \\ Timelia Tison ${ }^{2}$ and Javier Gordon Ogembo ${ }^{1,2}$ \\ ${ }^{1}$ Department of Experimental Therapeutics, Beckman Research Institute of City of Hope, Duarte, CA, USA \\ ${ }^{2}$ Department of Medicine, University of Massachusetts Medical School, Worcester, MA, USA \\ ${ }^{3}$ Department of Human Pathology, University of Nairobi, Nairobi, Kenya \\ Correspondence to: Javier Gordon Ogembo, email: jogembo@coh.org \\ Keywords: kaposi sarcoma-associated herpes virus, glycoproteins, virus-like particles, cancer, prophylactic vaccine \\ Received: September 24, $2016 \quad$ Accepted: January 16, $2017 \quad$ Published: February 22, 2017 \\ Copyright: Barasa et al. This is an open-access article distributed under the terms of the Creative Commons Attribution License (CC-BY), \\ which permits unrestricted use, distribution, and reproduction in any medium, provided the original author and source are credited.
}

\section{ABSTRACT}

Infection with Kaposi sarcoma-associated herpesvirus (KSHV) is estimated to account for over 44,000 new cases of Kaposi sarcoma annually, with $84 \%$ occurring in Africa, where the virus is endemic. To date, there is no prophylactic vaccine against KSHV. KSHV gpK8.1, $\mathrm{gB}$, and $\mathrm{gH} / \mathrm{gL}$ glycoproteins, implicated in the virus entry into host cells, are attractive vaccine targets for eliciting potent neutralizing antibodies (nAbs) against virus infection. We incorporated gpK8.1, gB, or $\mathrm{gH} / \mathrm{gL}$ on the surface of virus-like particles (VLPs) and characterized these VLPs for their composition, size, and functionality. To determine which viral glycoprotein(s) elicit the most effective serum-nAbs, we immunized BALB/c mice with gpK8.1, gB, or gH/gL VLPs individually or in combination. Neutralizing antibody assay revealed that sera from mice immunized with the VLPs inhibited KSHV infection of HEK-293 cells in a dosedependent manner. As a single immunogen, gpK8.1 VLPs stimulated comparable nAb activity to that of UV-inactivated KSHV (UV-KSHV). In contrast, UV-KSHV stimulated higher titers of $\mathrm{nAb}$ compared to $\mathrm{gB}(\mathrm{p}=0.0316)$ or $\mathrm{gH} / \mathrm{gL}(\mathrm{p}=0.0486)$. Mice immunized with the combination of $\mathrm{gB}$ and $\mathrm{gH} / \mathrm{gL}$ VLPs had a better $\mathrm{nAb}$ response than those immunized with either $\mathrm{gB}(\mathrm{p}=0.0268)$, or $\mathrm{gH} / \mathrm{gL}(\mathrm{p}=0.0397)$ as single VLP immunogens. Immunization with any VLP combination stimulated comparable nAb activity to UV-KSHV serum. Our data provide the first evidence that KSHV gpK8.1, $\mathrm{gB}$, and $\mathrm{gH} / \mathrm{gL}$ glycoproteins can be incorporated onto the surface of VLPs and used as prophylactic vaccine candidates, with potential to prevent KSHV infection.

\section{INTRODUCTION}

Kaposi sarcoma-associated herpesvirus (KSHV), also known as human herpesvirus-8 (HHV-8), is the etiologic agent of Kaposi sarcoma (KS), an endothelial cell tumor [1]. KSHV is also associated with primary effusion lymphoma and multicentric Castleman disease lymphoproliferative disorders [2]. KSHV transmission occurs mainly via saliva exchange, sexual contact, and rarely, through organ transplantation and blood transfusion
[3-9]. The seroprevalence of KSHV varies globally, with high rates in parts of Africa and South America (30-60\%, considered to be endemic), intermediate rates in the Mediterranean region (4-35\%), and low rates in North America, Western Europe, and Asia (<10\%) [10-13]. KS is most frequent in regions with high KSHV seroprevalence, such as African and Mediterranean countries [14].

KSHV-associated malignancies predominantly present in people with primary and acquired immunodeficiencies, including acquired immunodeficiency syndrome (AIDS) and 
iatrogenic immunosuppression in organ transplant recipients $[15,16]$. KS is one of the most frequent malignancies seen in AIDS patients $[17,18]$. It is a major cause of morbidity and mortality in adults in sub-Saharan Africa, where the prevalence of HIV/AIDS is high, and it is an emerging problem for children [19-21]. Despite a significant reduction in the incidence of $\mathrm{KS}$ since the introduction of highly active antiretroviral therapy (HAART), there are still approximately 44,000 new cases of KS worldwide each year, with $84 \%$ occurring in Africa [22]. Furthermore, only $50 \%$ of patients achieve complete resolution of KS lesions with HAART [23]. Thus, there is a need for improved preventive and therapeutic approaches to KS.

Prophylactic vaccines typically stimulate an individual's humoral immune system to produce neutralizing antibodies against the surface glycoprotein(s) mediating the infectious agent's entry $[24,25]$. The role of neutralizing antibodies in preventing KSHV infection or KSHVassociated malignancies has not been determined. To date, efforts to develop a prophylactic vaccine against KSHV have been lacking, with no preclinical or clinical vaccine trial reported in the past three decades, despite the AIDS pandemic [26]. A KSHV vaccine would be highly beneficial for at-risk populations, e.g., those at high risk of HIV infection, people living in $\mathrm{KSHV}$-endemic areas, or individuals undergoing iatrogenic immunosuppression after organ or stem cell transplantation. An effective KSHV vaccine could even eradicate the virus and its associated malignancies in areas where low seroprevalence rates are reported.

Like all other herpesviruses, KSHV enters target cells through a multi-step process that involves interactions between multiple viral envelope glycoproteins and host cell surface molecules that include attachment and fusion receptors [27, 28]. The KSHV envelope glycoproteins implicated in virus-cell attachment and fusion, and which facilitate viral entry are gpK8.1, gB, and $\mathrm{gH} / \mathrm{gL}$. Both gpK8.1 and $\mathrm{gB}$ are thought to initiate viral entry by binding to host cell surface heparan sulfate $[29,30]$. This leads to conformational changes that allow access to specific entry receptors, including integrins and ephrin receptors, which facilitate viral uptake into the host cells [31]. gB binds to integrin receptors, while $\mathrm{gH}$ and $\mathrm{gL}$ form a non-covalently linked complex that interacts with the ephrin receptor EphA2 [32]. Studies have shown that the $\mathrm{gH} / \mathrm{gL}$ complex is indispensable for viral entry, and that antibody blockade of $\mathrm{gH} / \mathrm{gL}$ affects KSHV target cell entry without affecting binding [33].

We developed KSHV envelope glycoproteinbased virus-like particles (VLPs) as prophylactic vaccine candidates. VLPs are self-assembling structures composed of one or more viral proteins. They can serve as delivery systems to present antigens from different types of pathogens [34]. The size and structure of VLPs closely resembles those of native virus, but they are non-infectious, as they lack viral genetic material. These qualities make VLPs a highly immunogenic and safe vaccine platform for oncogenic viruses such as KSHV [35].
This study demonstrates that targeting viral entry as a strategy for prevention of KSHV infection and its associated malignancies is feasible. We used the Newcastle disease virus (NDV) platform to generate VLPs bearing KSHV gpK8.1, gB, or $\mathrm{gH} / \mathrm{gL}$ envelope glycoproteins. We immunized wild-type BALB/c mice and measured neutralizing antibody response. Our results confirm that KSHV glycoprotein-based VLPs are immunogenic and generate a KSHV-specific immunoglobulin G ( $\mathrm{IgG}$ ) antibody response in immunized mice. In addition, in vitro neutralization assays performed using recombinant KSHV tagged with enhanced green fluorescent protein (KSHVeGFP) showed that antibodies generated by KSHV glycoprotein-based VLP-immunized mice can inhibit KSHV infection in vitro.

\section{RESULTS}

\section{Construction of chimeric gpK8.1-F, gB-F, gH-F, and gL-HN cDNA plasmids, and purification and characterization of KSHV VLPs}

To generate KSHV gpK8.1 VLPs, we first designed and synthesized a chimeric KSHV gpK8.1-F construct by fusing the KSHV gpK8.1 ectodomain to the NDV fusion protein $(\mathrm{F})$ heptad repeat 2 (HR2), transmembrane (TM), and cytoplasmic (CT) domains (Figure 1A). The construct was cloned into a mammalian expression vector (pCAGGS) and the fidelity of the chimeric gene was verified by sequencing.

To demonstrate that chimeric gpK8.1-F is functionally expressed on the surface of cells, we transfected Chinese hamster ovary $(\mathrm{CHO})$ cells with the gpK8.1-F plasmid or relevant controls. Forty-eight hours post-transfection, cells were stained with anti-gpK8.1 mouse monoclonal antibody (mAb), which detects the ectodomain of the protein, followed by secondary antimouse antibody conjugated to Alexa Fluor (AF488) fluorochrome. Flow cytometry showed that $\mathrm{CHO}$ cells transfected with the pCAGGS-gpK8.1-F chimera robustly expressed gpK8.1 (88\% expression), similar to cells transfected with pCAGGS-gpK8.1 full-length (WT) (82\% expression), which served as a positive control (Figure 1B). Cells transfected with empty pCAGGS vector (negative control) did not express gpK8.1.

To assemble and produce gpK8.1 VLPs, equal amounts of gpK8.1-F, NDV-matrix (M), and NDVnucleocapsid protein (NP) cDNA plasmids were cotransfected into $\mathrm{CHO}$ cells (Figure 1C). The cell supernatant containing VLPs was collected every $24 \mathrm{~h}$ until $96 \mathrm{~h}$ post-transfection. VLPs were purified as previously described $[25,36]$.

To confirm that gpK8.1, NP, and $M$ were incorporated into gpK8.1 VLPs, we lysed purified VLPs in RIPA buffer and analyzed the lysates for protein composition by immunoblot (Figure 2A). As expected, 


\section{A. Chimeric-gpK8.1-F}

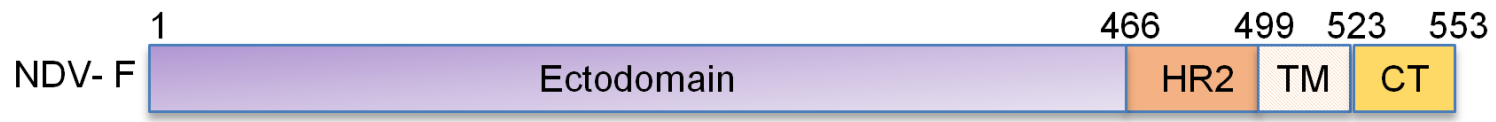

\begin{tabular}{l|l|l|l|l|r|} 
& 162 & 185197 & 207 & 228 \\
gpK8.1 WT & Ectodomain & & TM & CT \\
\hline
\end{tabular}

\begin{tabular}{|c|c|c|c|c|}
\hline & 162 & 18519723 & 3025 & 2 \\
\hline gpК8.1-F & Ectodomain & HR2 & TM & CT \\
\hline
\end{tabular}

\section{B. Expression of gpK8.1-F protein on the surface of $\mathrm{CHO}$ cells}
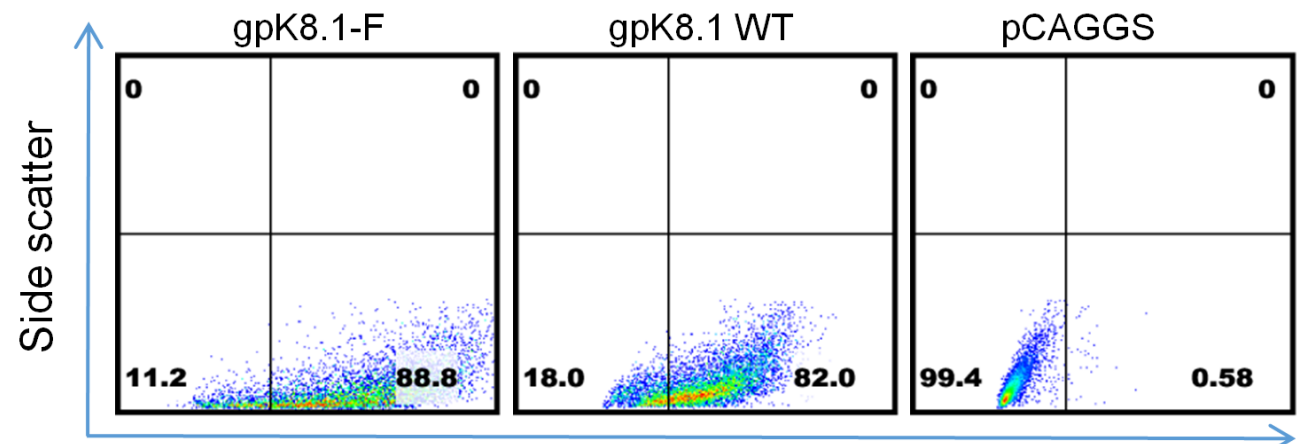

Mean fluorescence intensity (mAb-anti gpK8.1-AF488)

\section{Generation of K8.1 VLPs}
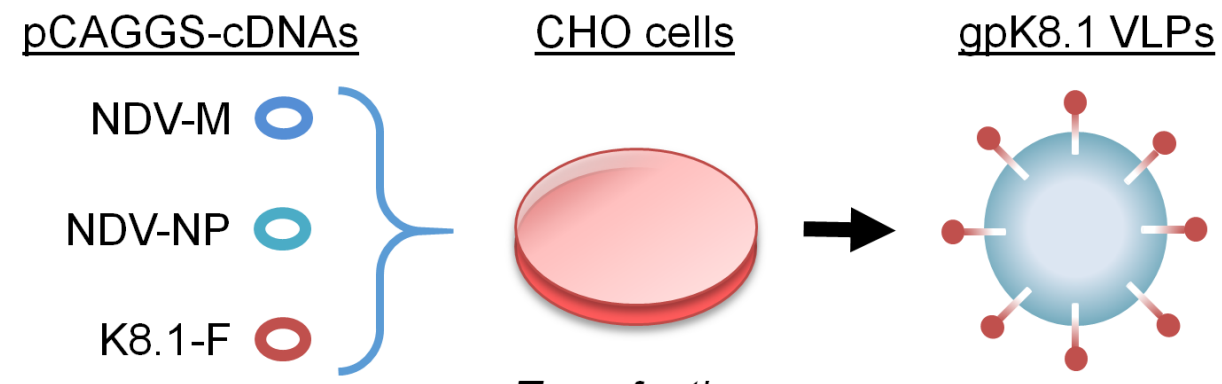

Transfection

Figure 1: Schematic representation of the construction of chimeric KSHV gpK8.1-F and production of gpK8.1 VLPs. A. gpK8.1-F plasmid constructs (not to scale) showing full-length NDV-F (top), full-length/wild-type (WT) gpK8.1 (middle), and chimeric gpK8.1-F (bottom). B. Flow cytometric analysis for surface expression of gpK8.1 protein on $10^{6} \mathrm{CHO}$ cells transfected with $1 \mu \mathrm{g}$ of pCAGGS gpK8.1-F chimera, pCAGGS gpK8.1 WT (positive control), and empty pCAGGS vector (negative control) was performed at $48 \mathrm{~h}$ post-transfection. Transfected cells were resuspended in PBS, stained with anti-gpK8.1 mAb, which detects the ectodomain of the protein, followed by secondary antibody goat-anti-mouse IgG conjugated to AF488. From left, gpK8.1-F chimeric protein is robustly expressed on the surface of CHO cells, similar to WT gpK8.1 (middle panel), and no gpK8.1 protein was detected in CHO cells transfected with pCAGGS alone (negative control). C. Illustration of co-transfection of CHO cells with three cDNA plasmids required to make VLPs, pCAGGS cDNAs NDV-M, NDV-NP and gpK8.1-F, resulting in release of fully-assembled gpK8.1 VLPs. cDNAs NDV-M and NDV-NP have been described (see Materials and Methods). 


\section{A. Immunoblots of gpK8.1 VLPs}

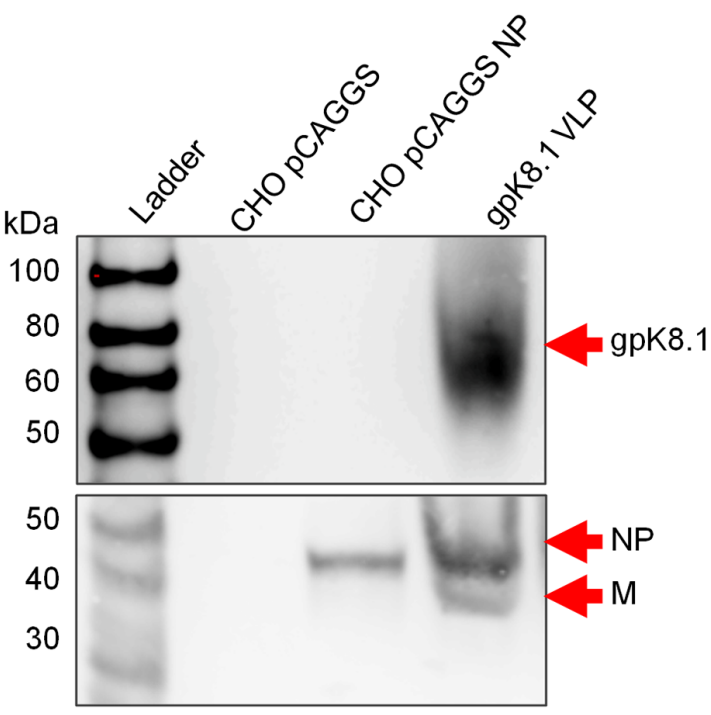

C. Electron micrograph of gpK8.1 VLPs

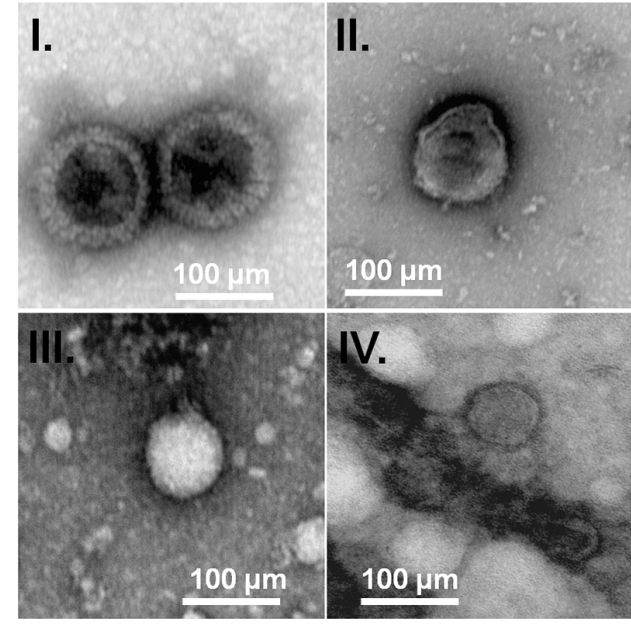
I. KSHVEM $(92 \mathrm{KX})$
II. $\quad$ gpK8.1 VLP $(92 \mathrm{KX})$
III. gpK8.1 VLP $(92 \mathrm{KX})$
IV. gpK8.1 VLP $(140 \mathrm{KX})$

B. Silver stain of gpK8.1-F VLPs

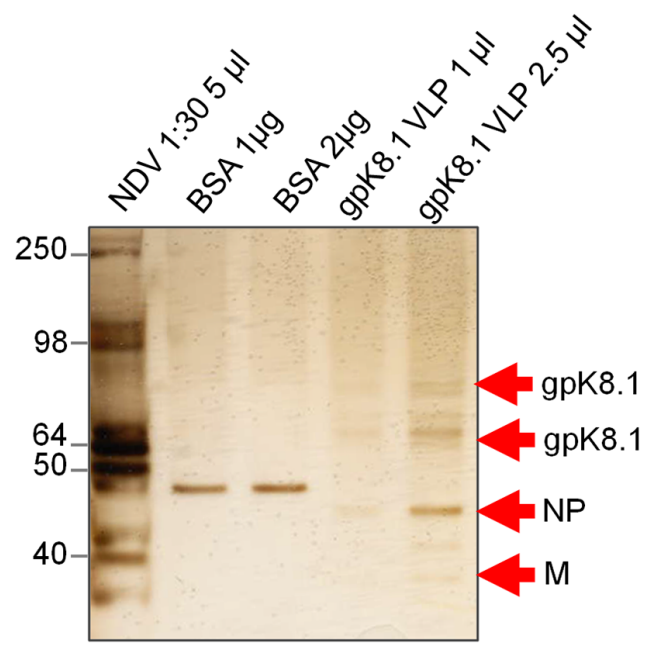

Figure 2: Characterization of KSHV gpK8.1 VLPs. A. CHO cells transfected with empty pCAGGS or pCAGGS-NP, or purified gpK8.1 VLPs were lysed and analyzed by immunoblot using anti-gpK8.1 mAb and rabbit polyclonal anti-NDV to detect various VLP components. Anti-gpK8.1 (top panel) detected gpK8.1 (62-72 KDa) in VLP lysate (lane 4), but not in CHO pCAGGS or CHO NP (negative controls, lanes 2-3). Anti-NDV (bottom panel; a gift of Dr. T. Morrison, University of Massachusetts Medical School) detected NP alone in lysate from CHO NP (lane 3), and NP and M in gpK8.1 VLPs (lane 4), but not in CHO pCAGGS lysate (negative control, lane 2). B. Silver stain was used to visualize VLP purity relative to purified NDV. Arrows indicate viral/VLP components in $5 \mu 1$ purified NDV diluted 1:30 (lane 1), and $1 \mu 1$ and $2.5 \mu \mathrm{l}$ of purified gpK8.1 VLPs diluted 1:40 (lanes 4-5). Lanes 2 and 3 were loaded with $1 \mu \mathrm{g}$ and $2 \mu \mathrm{g}$ BSA, respectively for protein quantification. C. Electron microscopy showing structural similarity between KSHV virions and gpK8.1 VLPs. Purified VLPs were dialyzed against 1 L TNE buffer to remove residual sucrose, incubated with 3\% bovine serum albumin (BSA) in TNE for $45 \mathrm{~min}$, and embedded on a grid. $5 \mu \mathrm{l}$ of the virus/VLP at 1:40 dilution was individually added to the grid for $1 \mathrm{~h}$ at room temperature. After two final washes, the grids were negatively stained with $12 \%$ phosphotungstic acid ( $\mathrm{pH} 7$ ) for 15 sec, air dried for 30 min, and examined using a Tecnai transmission electron microscope (FEI). D. Confocal microscopy shows gpK8.1 VLPs binding to lipid rafts on HMC-1 cells. Purified gpK8.1 VLPs were incubated with HMC-1 cells for $10 \mathrm{~min}$ at room temperature and stained with anti-gpK8.1, followed by secondary antibody conjugated with Alexa-Fluor 594 (red) to detect gpK8.1 VLPs, cholera toxin (green) to detect lipid rafts, and DAPI (blue) to detect HMC-1 nuclei. The red and green staining shows VLPs bound cell membranes; HMC-1 cells not incubated with VLPs did not stain red (negative control, inset). VLPs (red) binding to lipid rafts are not seen in HMC-1 cells not incubated with VLPs (negative control, inset). 
anti-gpK8.1 mAb detected gpK8.1 $(\sim 60-72 \mathrm{kDa})$ in purified VLPs (top panel, lane 4). No gpK8.1 protein was detected in lysates from $\mathrm{CHO}$ cells transfected with either empty pCAGGS vector or pCAGGS-NP (negative controls). Detection with rabbit polyclonal anti-NDV recognized NDV-NP in cells transfected with pCAGGSNP and both NDV-NP and -M components in purified VLPs (bottom panel, lanes 3-4). No NDV components were detected in $\mathrm{CHO}$ cells transfected with empty pCAGGS vector (negative control). Immunoblot of gpK 8.1 VLPs relative to additional controls (irrelevant Epstein-Barr VLPs, purified NDV, lytically induced iSLK.219 KSHV-eGFP-expressing cells, purified EpsteinBarr virus, and iSLK cells) confirmed that KSHV VLPs contained only the expected components (Supplementary Figure 1).

To assess the purity of gpK8.1 VLPs, we used silver stain; NDV lysate served as a positive control, and BSA was used for quantification of proteins. Bands of predicted sizes were detected for gpK8.1 (60-72 kDa), NDV-NP $(\sim 50 \mathrm{kDa})$, and NDV-M (35-45 kDa) (Figure 2B). Electron microscopy of gpK8.1 VLPs confirmed that gpK8.1 VLPs structurally resembled KSHV (Figure 2C).

To confirm that chimeric gpK8.1-F proteins incorporated into VLPs were in the right conformation and able to bind cellular surface receptors, purified gpK8.1 VLPs were incubated with human mast cells 1 (HMC-1) susceptible to KSHV infection. Cells incubated with VLPs were stained with anti-gpK8.1 mAb conjugated with AF-594 (red) to detect gpK8.1 VLPs, cholera toxin (green) to detect lipid rafts, and DAPI (blue) to detect HMC-1 nuclei (Figure 2D). HMC-1 cells not incubated with VLPs were used as negative control (inset). Stained cells were analyzed by confocal microscopy as described in Materials and Methods, and showed binding of VLPs to the lipid rafts in the cell membranes of VLP-incubated cells, indicative of functional binding.

Upon successful generation and characterization of gpK8.1 VLPs, we used a similar strategy to generate $\mathrm{KSHV} \mathrm{gB}$ and $\mathrm{KSHV} \mathrm{gH} / \mathrm{gL}$ VLPs. To generate KSHV gB VLPs, we synthesized a chimeric gB-F construct by fusing the KSHV gB ectodomain to the NDV-F HR2, TM, and $\mathrm{CT}$ domains (Figure 3A). The construct was cloned into the pCAGGS expression vector, sequence verified, and used to co-transfect $\mathrm{CHO}$ cells, together with equal amounts of NDV-NP and NDV-M. KSHV gB VLPs were purified as previously described $[25,36]$. We confirmed expression of component proteins gB, NDV-M, and NDVNP using immunoblot of purified gB VLPs and relevant controls. Due to lack of an effective commercial antibody that has been optimized against KSHV gB, we detected the gB-F fusion protein using anti-NDV F tail. Anti-F tail predominantly detected the cleaved forms of the gB-F fusion protein $(\sim 75$ and $\sim 55 \mathrm{kDa})$. Anti-NDV detected NDV-NP in CHO cells transfected with pCAGGS-NP (positive control), and NP and M in gB-F VLPs, but not in $\mathrm{CHO}$ cells transfected with empty pCAGGS vector (negative control) (Figure 3B).

To assess purity, and to confirm detection of the various components of the gB VLP, we used silver stain. NDV lysate was used as a positive control, and BSA was used for quantification of protein. KSHV gB is synthesized as a $110-\mathrm{kDa}$ precursor protein which undergoes furin cleavage and processing to yield envelope-associated disulfide-linked 75- and 55-kDa polypeptides [37]. Bands of predicted sizes were detected for uncleaved ( 110 $\mathrm{kDa})$ and furin-cleaved $\mathrm{gB}(\sim 75$ and $55 \mathrm{kDa})$, NDV-NP $(\sim 50 \mathrm{kDa})$, and NDV-M (35-45 kDa) (Figure 3C). To confirm that $\mathrm{gB}-\mathrm{F}$ proteins incorporated on the surface of VLPs were functional and bound cell surface receptors, we incubated purified gB VLPs with HMC-1 cells and performed immunofluorescent confocal microscopy, as above. Cells incubated in the presence, but not the absence (inset), of gB VLPs showed binding of VLPs (red) with lipid rafts in cell membranes (green), indicative of functional binding (Figure 3D).

To generate KSHV gH/gL VLPs, we synthesized chimeric gH-F and gL-HN constructs by fusing the KSHV gH ectodomain to the NDV-F HR2, TM, and CT domains (Figure 4A), and the KSHV gL ectodomain to the NDV hemagglutinin-neuraminidase protein (NDV-HN) TM and CT domains (Figure 4B). The rationale for fusion of a type 1 membrane protein (i.e., $\mathrm{gH}$ ) to NDV-F protein and a type 2 membrane protein (i.e., gL) to NDV-HN has been described [38]. Synthesized cDNA constructs (gH-F and gL-HN) were individually cloned into the pCAGGS expression vector, sequence verified, and used to co-transfect $\mathrm{CHO}$ cells with NDV-NP and -M. VLPs were purified as previously described $[25,36]$. To confirm protein components of purified VLPs we performed immunoblot analysis with purified VLPs lysed in RIPA buffer (Figure 4C). Due to lack of an effective commercial antibody optimized against $\mathrm{KSHV} \mathrm{gH} / \mathrm{gL}$ for immunoblot, we detected the $\mathrm{gH}-\mathrm{F}$ chimeric protein using anti-NDV F HR2 domain (top panel). Anti-HR2 detected the gH-F component in purified $\mathrm{gH} / \mathrm{gL}$ VLPs $(5 \mu \mathrm{g}$ and $10 \mu \mathrm{g})$, but not in CHO cells transfected with empty pCAGGS vector, pCAGGS NDV-NP, or wild-type $\mathrm{gH}$ or $\mathrm{gL}$, or in lysates from lytically induced iSLK.219 KSHV-eGFPexpressing cells (negative controls). Anti-NDV detected NDV-NP and -M on gH/gL VLPs and NP alone in CHO cells transfected with pCAGGS-NP (positive control), but not in $\mathrm{CHO}$ cells transfected with empty pCAGGS vector, $\mathrm{CHO}$ cells transfected with wild-type $\mathrm{gH}, \mathrm{gL}$, or chimeric gH-F, or in iSLK.219 lysate (negative controls) (bottom panel). Further immunoblot analysis of $\mathrm{gH} / \mathrm{gL}$ proteins using unpurified sera from mice immunized with $\mathrm{gH} / \mathrm{gL}$ VLPs confirmed VLP composition to include gH, gL, NP and $\mathrm{M}$ (Supplementary Figure 2).

To assess purity of the $\mathrm{gH} / \mathrm{gL}$ VLPs, and to confirm expression of the $\mathrm{gH}$ and $\mathrm{gL}$ protein components, we used silver stain. NDV lysate was used as a positive control, and 


\section{A: Chimeric gB-F}

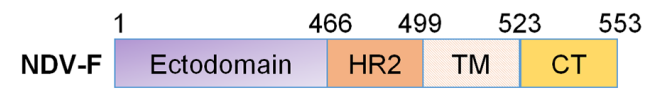

\begin{tabular}{|c|c|c|c|c|}
\hline & & 736 & 753 & \\
\hline gB WT & Ectodomain & TM & & CT \\
\hline & & $730 \quad 763$ & 787 & 817 \\
\hline gB-F & Ectodomain & HR2 & TM & CT \\
\hline
\end{tabular}

\section{B. Immunoblots of gB VLPs}

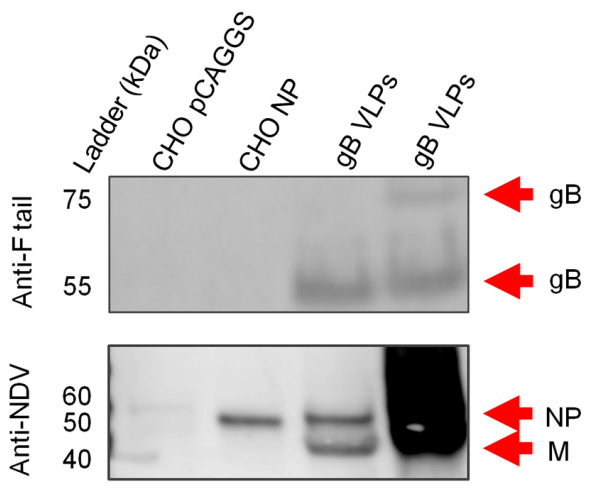

\section{Silver stain of gB VLPs}

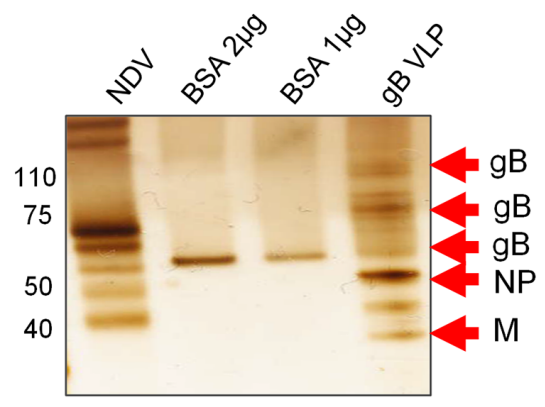

D. gB VLPs bind to HMC-1 cell line

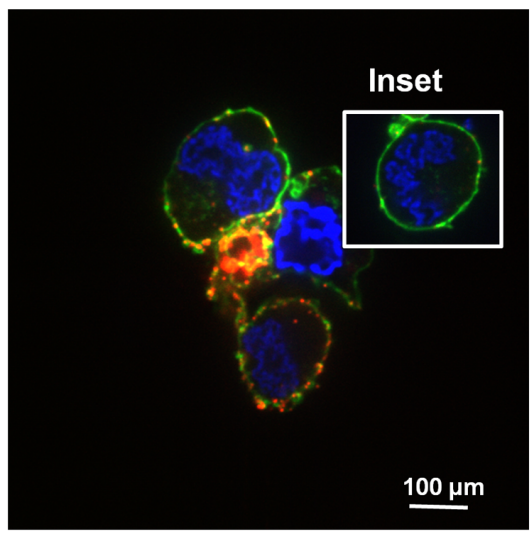

Figure 3: Construction of KSHV gB-F and characterization of KSHV gB VLPs. A. KSHV gB-F plasmid constructs (not to scale) showing full-length NDV-F (top), full-length/wild-type (WT) gB (middle), and chimeric gB-F (bottom). B. CHO cells transfected with empty pCAGGS vector or pCAGGS-NP, or purified gB VLPs were lysed and analyzed by immunoblot using polyclonal anti-NDV $\mathrm{F}$ tail and anti-NDV. Anti-F tail (top panel) detected the cleaved forms of the gB-F fusion protein ( $\sim 55$ and $\sim 75 \mathrm{kDa})$ in $5 \mu \mathrm{g}$ and $10 \mu \mathrm{g}$ of purified gB VLPs (lanes 3-4), but not in CHO pCAGGS or CHO NP lysates (negative controls, lanes 1-2). Anti-NDV (bottom panel) detected NP alone in CHO NP (positive control, lane 2), and NP and M in gB VLPs (lanes 3-4), but not in CHO pCAGGS (negative control, lane 1). C. Silver stain was used to visualize VLP purity relative to purified NDV, and detected uncleaved and cleaved gB-F proteins of $\sim 110$, and $55-75 \mathrm{kDa}$. Arrows indicate viral/VLP components in $5 \mu$ l purified NDV diluted 1:30 (lane 1), and $1 \mu 1$ purified gB VLPs diluted 1:40 (lane 4). Lanes 2 and 3 were loaded with $1 \mu \mathrm{g}$ and $2 \mu \mathrm{g}$ BSA, respectively for protein quantification. D. Confocal microscopy shows $\mathrm{gB}$ VLPs binding to surface receptors on HMC-1 cells. Purified gB VLPs were incubated with HMC-1 cells for 10 min at room temperature and stained with rabbit polyclonal anti-gB, followed by secondary antibody conjugated with Alexa-Fluor 594 (red) to detect gB VLPs, cholera toxin (green) to detect lipid rafts, and DAPI (blue) to detect HMC-1 nuclei. The red and green staining shows VLPs bound cell membranes; HMC-1 cells not incubated with VLPs did not stain red (negative control, inset). 


\section{A: Chimeric $\mathbf{g H}-\mathrm{F}$}

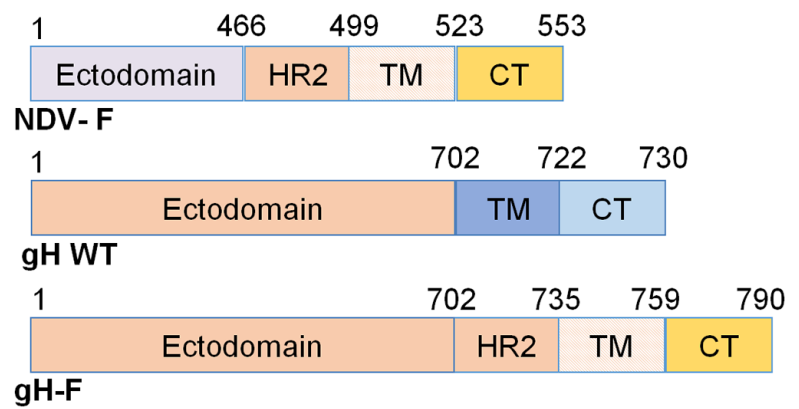

\section{Immunoblots of $\mathrm{gH} / \mathrm{gL}$ VLPs}

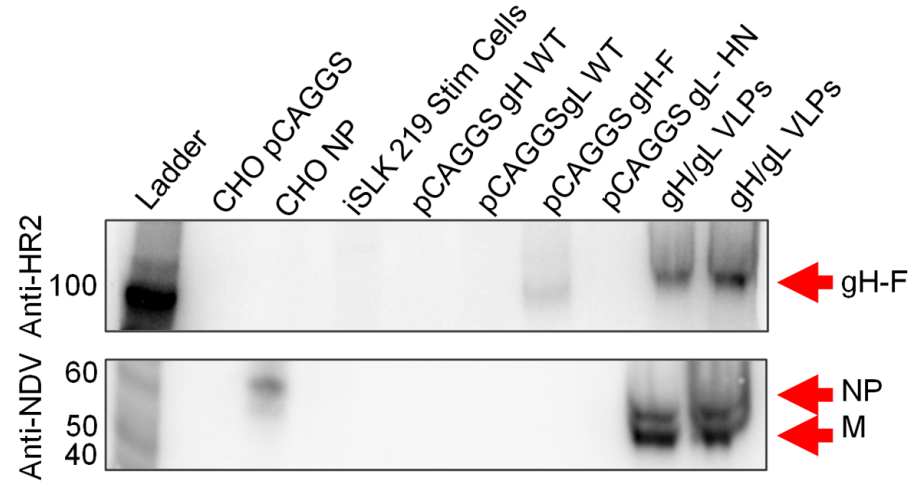

B: Chimeric gL-HN

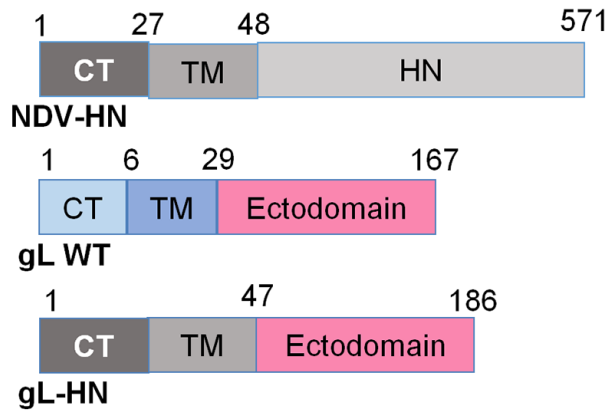

\section{Silver stain of $\mathrm{gH} / \mathrm{gL}$ VLPs}

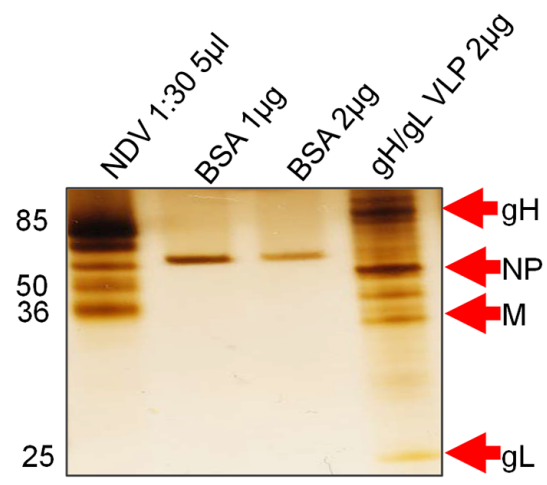

\section{E. $\mathrm{gH} / \mathrm{gL}$ VLPs bind to HMC-1 cell line}

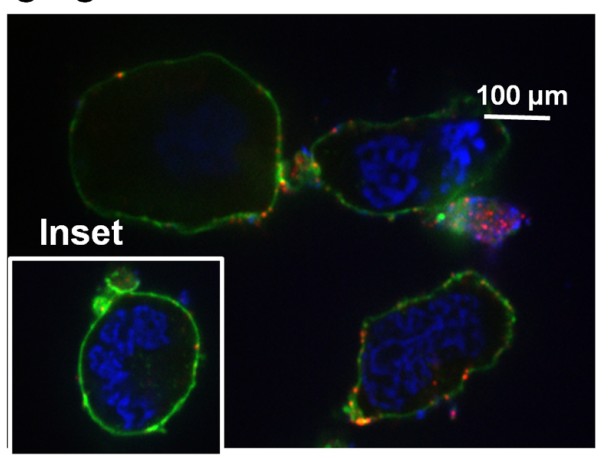

Figure 4: Construction of KSHV gH-F/gL-HN and characterization of KSHV gH/gL VLPs. A. gH-F plasmid constructs (not to scale) showing full-length NDV-F (top), full-length/wild-type (WT) gH (middle), and chimeric gH-F (bottom). B. gL-HN plasmid constructs (not to scale) showing full-length NDV-HN (top), full-length/WT gL (middle), and chimeric gL-HN (bottom). C. Purified gH/ gL VLPs, CHO cells transfected with pCAGGS, pCAGGS-NP, -gH WT, -gL WT, -gH-F, gL-HN, and lytically induced iSLK KSHV-eGFP expressing cells were lysed in RIPA buffer and analyzed by immunoblot with polyclonal anti-NDV F HR2 and anti-NDV. Anti-HR2 detected gH-F in $5 \mu \mathrm{g}$ and $10 \mu \mathrm{g}$ gH/gL VLPs (lanes 9-10) and in CHO gH-F cells (positive control, lane 7), but not other samples (negative controls). Anti-NDV (bottom panel) detected NP alone in CHO NP (positive control, lane 3), and NP and M in gB VLPs (lanes 9-10), but not in other samples (negative controls). For detection of $\mathrm{gL}-\mathrm{HN}$ using polyclonal antibody raised from mice immunized with $\mathrm{gH} / \mathrm{gL}$ VLPs see Supplementary Figure 2. D. Silver stain was used to visualize VLP purity relative to purified NDV. Arrows indicate viral/VLP components in $5 \mu 1$ purified NDV diluted 1:30 (lane 1), and $2 \mu 1$ purified gH/gL VLPs diluted 1:40 (lane 4). Lanes 2 and 3 were loaded with $1 \mu \mathrm{g}$ and $2 \mu \mathrm{g}$ BSA, respectively for protein quantification. E. Confocal microscopy shows gH/gL VLPs binding to surface receptors on HMC-1 cells. Purified gH/gL VLPs were incubated with HMC-1 cells for 10 min at room temperature and stained with anti-gH, followed by secondary antibody conjugated with Alexa-Fluor 594 (red) to detect gH/gL VLPs, cholera toxin (green) to detect lipid rafts, and DAPI (blue) to detect HMC-1 nuclei. The red and green staining shows VLPs bound cell membranes; HMC-1 cells not incubated with VLPs did not stain red (negative control, inset). 
BSA ( $1 \mu \mathrm{g}$ and $2 \mu \mathrm{g}$ ) was used for quantification of protein. Bands of predicted sizes were detected for $\mathrm{gH}(85 \mathrm{kDa}), \mathrm{gL}$ (25 kDa), NDV-NP ( 50 kDa), and NDV-M (35-45 kDa) (Figure 4D). To confirm that the VLPs were functional and bound cell surface receptors, we incubated purified $\mathrm{gH} / \mathrm{gL}$ VLPs with HMC-1 cells and performed immunofluorescent confocal microscopy, as above. Cells incubated in the presence, but not the absence (inset), of $\mathrm{gH} / \mathrm{gL}$ VLPs showed binding of VLPs (red) with lipid rafts in cell membranes (green), indicative of functional binding (Figure 4E).

\section{KSHV VLPs stimulate KSHV-specific IgG antibody responses in immunized $B A L B / c$ mice}

To test the ability of individual KSHV envelope glycoprotein-based VLPs to stimulate KSHV-specific antibody responses, three groups of five female BALB/c mice each were immunized intraperitoneally with $10 \mu \mathrm{g}$ of purified gpK8.1, gB, or gH/gL VLPs suspended in $0.5 \mathrm{ml}$ of TNE buffer without adjuvants. Two groups of five mice each were immunized with TNE buffer alone (negative control) or UV-inactivated KSHV (positive control). To test additive or synergistic effects of two or more KSHV glycoprotein immunogens [39], we also immunized four groups of five mice each with two or three individual VLPs (gpK8.1 and gB; gpK8.1 and gH/gL; gB and gH/ $\mathrm{gL}$; or gpK8.1, gB, and $\mathrm{gH} / \mathrm{gL}$ ).

The mice were immunized at Day 0 and boosted twice, on Days 29 and 54. Mice were tail-vein bled on Days 14, 46, and 84, with a terminal bleed on Day 133 (Figure 5A).

To demonstrate the ability of KSHV VLPs to induce KSHV-specific antibody responses, we used ELISA to determine the presence of anti-KSHV IgG antibodies in sera of immunized mice. Lysate from lytically induced iSLK.219 KSHV-eGFP-expressing cells, which express all KSHV envelope glycoproteins, served as the binding target. Sera from all bleeding time-points were analyzed. All VLP-immunized mice generated KSHV-specific IgG antibody responses that increased following booster immunizations, compared with TNE-immunized mice (negative control) (Figure 5B). The increase in KSHVspecific antibody response peaked by Day 84 , after the second booster immunization, similarly to UV-inactivated KSHV-immunized mice (positive control). The antibody responses to the KSHV-envelope glycoprotein-based VLPs were long-lived, as the titers were still high even after 133 days. A detailed analysis of serum antibody responses in individual mice at each time point is provided in Supplementary Figure 3.

\section{Antibodies from mice immunized with KSHV VLPs neutralize KSHV infection in vitro}

To assess the ability of VLP-immunized sera to neutralize KSHV infection in vitro, sera collected at Day
133 were used to conduct KSHV infection neutralization assays. HEK-293 cells were used as the host for the neutralization assays, as a model of epithelial cells that are susceptible to KSHV infection [40]. Cells were exposed to KSHV-eGFP purified from lytically induced iSLK.219 cells in the absence or presence of sera from VLP-immunized animals. The virus titer was determined by an infectivity assay, as previously described [25] and as briefly outlined in Materials and Methods sections. Known KSHV-positive plasma (488HO4), a gift of Dr. Wood, University of Nebraska, Lincoln, served as positive control and neutralized $>80 \%$ of KSHV infection at $1: 6,1: 9$, and 1:18 dilutions. Sera from mice immunized with TNE (data not shown) served as negative control and was used to normalize the percent infection. Upon pre-incubation of 60 $\mu \mathrm{l}$ of KSHV-eGFP with sera from mice immunized with KSHV glycoprotein-based VLPs, infection of HEK-293 cells was reduced with increasing antibody concentration (Figure 6). At a 1:18 serum dilution, pooled serum from individual mice immunized with a combination of either gB-gH/gL, gpK8.1-gB-gH/gL, or gpK8.1-gH/gL VLPs showed the best neutralization, inhibiting infection by $63.5 \%, 51 \%$, and $54.7 \%$ respectively, compared to $<50 \%$ for the mice immunized with single gpK8.1, gB, or $\mathrm{gH} /$ gL VLPs.

Data from three independent experiments at a 1:9 serum dilution were used to determine the effectiveness of each glycoprotein in eliciting neutralizing antibodies as a single or combined immunogen(s) (Figure 7). Sera from mice immunized with a gpK8.1 VLPs as a single immunogen stimulated comparable neutralizing antibody activity to UV-inactivated KSHV. In contrast, immunization with $\mathrm{gB}$ or $\mathrm{gH} / \mathrm{gL}$ VLPs as single immunogens stimulated a less effective neutralizing antibody responses compared to UV inactivated-KSHV ( $\mathrm{p}=0.0316, \mathrm{p}=0.0486$, respectively). Immunization with a combination of $\mathrm{gB}$ and $\mathrm{gH} / \mathrm{gL}$ VLPs had a better neutralizing antibody response than either single immunogen, $\mathrm{gB}(\mathrm{p}=0.0119)$, or $\mathrm{gH} / \mathrm{gL}(\mathrm{p}=0.0133)$. Importantly, immunization with any combination containing gpK8.1 VLPs (gpK8.1-gB, gpK8.1-gH/gL, and gpK8.1-gB-gH/gL) stimulated comparable neutralizing antibody activity to UV-inactivated KSHV. Our findings confirm that immunization with a combination of immunogens has an additive effect on immunogenicity and neutralizing antibody response.

\section{DISCUSSION}

KS is a significant cause of morbidity and mortality in sub-Saharan Africa. Primary prevention by vaccination against KSHV could play an important role in limiting virus shedding and transmission, thus reducing the burden of KS in KSHV-endemic areas. To the best of our knowledge, this is the first study to generate VLPs using KSHV glycoproteins gpK8.1, $\mathrm{gB}$, or $\mathrm{gH} / \mathrm{gL}$ as target 
immunogens to serve as prophylactic vaccine candidates for prevention of KSHV infection.

We showed that co-transfection of $\mathrm{CHO}$ cells with chimeric KSHV envelope glycoproteins and NDV structural proteins leads to successful production of gpK8.1, gB, and gH/gL VLPs. These VLPs resemble native virus and bind the KSHV-susceptible HMC-1 cell line, demonstrating that the conformation of the viral glycoproteins is conserved and functional.

Importantly, immunization of female wild-type BALB/c mice with KSHV glycoprotein-based VLPs singly or in combination induced humoral immune responses, resulting in moderately high titers of serum antibodies relative to UV-inactivated KSHV. Antibody

\section{A. Mice immunization and bleeding schedule}

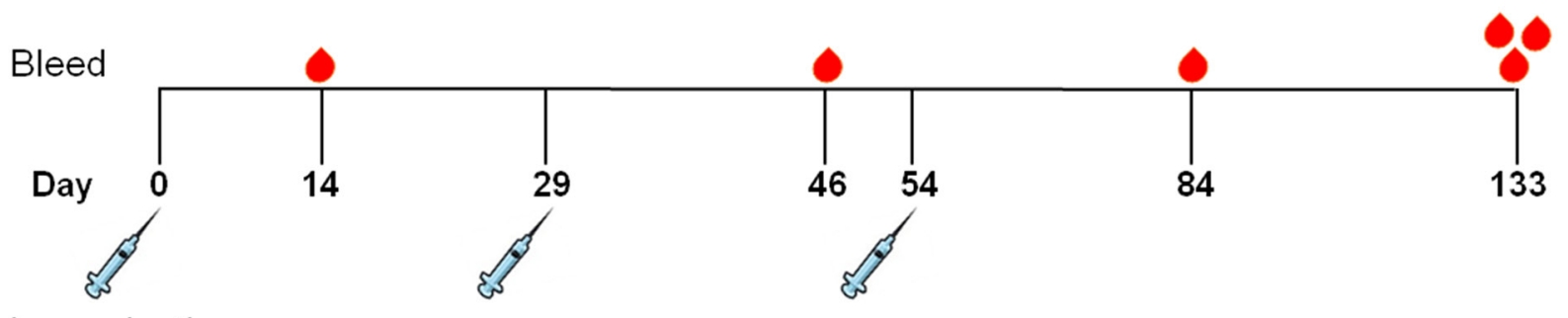

Immunization

\section{B. Antibody responses in immunized mice}

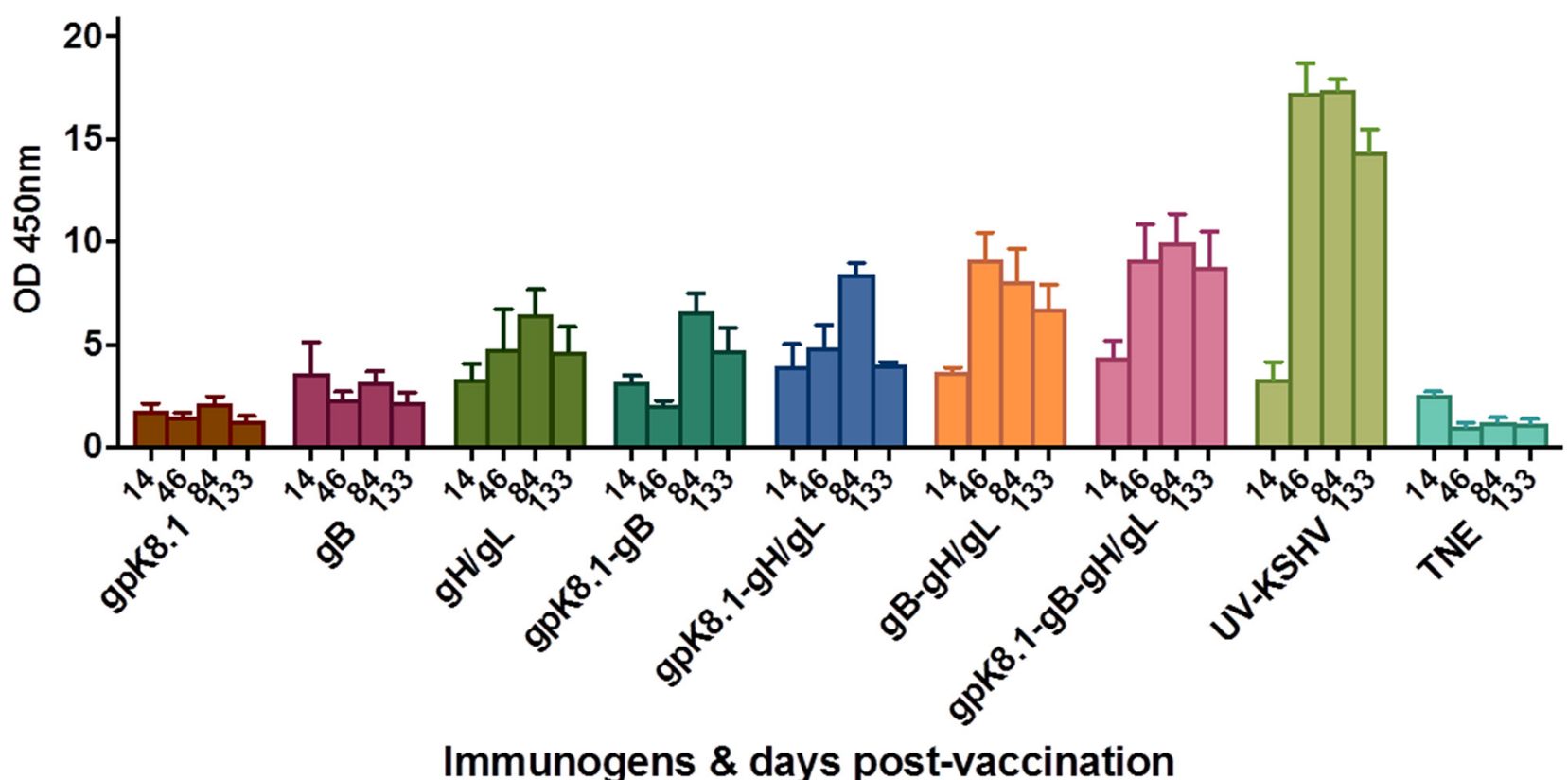

Figure 5: Immunization and generation of specific anti-KSHV IgG antibody responses in BALB/c mice. A. Immunization and bleeding schedule of 6-8-week-old female BALB/c mice. A total of 9 groups of five BALB/c mice each were immunized with $10 \mu \mathrm{g}$ of purified gpK8.1, gB, or gH/gL VLPs, or a combination of gpK8.1 and gB; gpK8.1 and gH/gL; gB and gH/gL; or gpK8.1, gB, and gH/ gL VLPs. Two groups were immunized with either $10 \mu \mathrm{g}$ of purified UV-inactivated KSHV (positive control) in TNE buffer, or TNE buffer alone (negative control). The immunizations were administered on Day 0 (primary), followed by two boosts on Days 29 and 54 , respectively. Mice were tail-vein bled on Days 14, 46, and 84, followed by terminal bleed on Day 133. B. Antibody titers in sera from immunized BALB/c mice were determined by ELISA using lysate from lytically induced iSLK.219 KSHV-eGFP-expressing cells as target antigen. Serum samples from Days 14, 46, 84, and 133 diluted 1:100 in PBS were incubated in microtiter plates coated with iSLK.219 KSHV-eGFP cell lysate. Lysates from iSLK cells (free of KSHV infection) and irrelevant ELL-0 cell lines were used as negative controls. Antibody binding was detected using HRP-labeled goat anti-mouse IgG secondary antibody. The absorbance resulting from serum antibody binding to KSHV-eGFP-expressing iSLK.219 cell lysate target antigen is shown as summary data for each group of mice. Absorbance data are shown as the mean (top of bar) \pm the SEM (error bar above bar) for five mice per group (see Supplementary Figure 3 for individual mice at 2 time-point). KSHV VLPs induced increasing titers of anti-KSHV specific IgG antibodies after each immunization. 
titers peaked after the second boost immunization and did not significantly decrease until Day 133, suggesting that VLPs can induce long-term immunogenicity in mice. This also provides circumstantial evidence that memory plasma cells are developed in response to vaccination with KSHV glycoprotein-based VLPs.

UV-inactivated KSHV induced higher titers of KSHV-specific IgG antibodies than KSHV glycoproteinbased VLPs administered singly or in combination, suggesting it was a better immunogen. However, the high antibody titers detected in response to UV-inactivated KSHV could be due to non-target-specific binding, possibly to UV-inactivated KSHV itself, or due to the presence of other antibodies directed to the iSLK.219 cells used for virus production and as the target lysate in ELISA. Furthermore, whether some threshold level of vaccine-induced antibody titer is required to prevent infection in vivo remains to be elucidated in an appropriate animal model. A humanized mouse model [41] and nonhuman primate model [42] have been developed and characterized to support studies of KSHV infection, and would be ideal for demonstrating in vivo efficacy of candidate vaccines in future studies. If increased antibody titers are required to prevent infection in vivo, we could increase immunogenicity by administering the KSHV glycoprotein-based VLPs in the presence of adjuvant [43], or by titrating the VLP concentration to achieve an optimal dose to elicit effective KSHV-specific neutralizing antibody titers [44].

Neutralizing antibodies can inhibit progression of herpesvirus-associated diseases [45-47]. Thus, a vaccine that elicits a neutralizing antibody response could help prevent KSHV infection and its associated malignancies in KSHV-endemic populations [48]. The KSHV glycoprotein-based VLPs induced neutralizing antibody responses in all immunized mice. The neutralizing antibodies blocked KSHV infection in vitro in a dose-dependent manner. Immunization with a single immunogen, gpK8.1, induced neutralizing antibody activity that was comparable to UV-inactivated KSHV, the gold standard. Immunization with a combination of $\mathrm{gB}$ and $\mathrm{gH} / \mathrm{gL}$ VLPs induced a better neutralizing antibody response than either immunogen on its own. Importantly, combination of gpK8.1 with any other KSHV

\section{Antibody-mediated inhibition of KSHV infection}

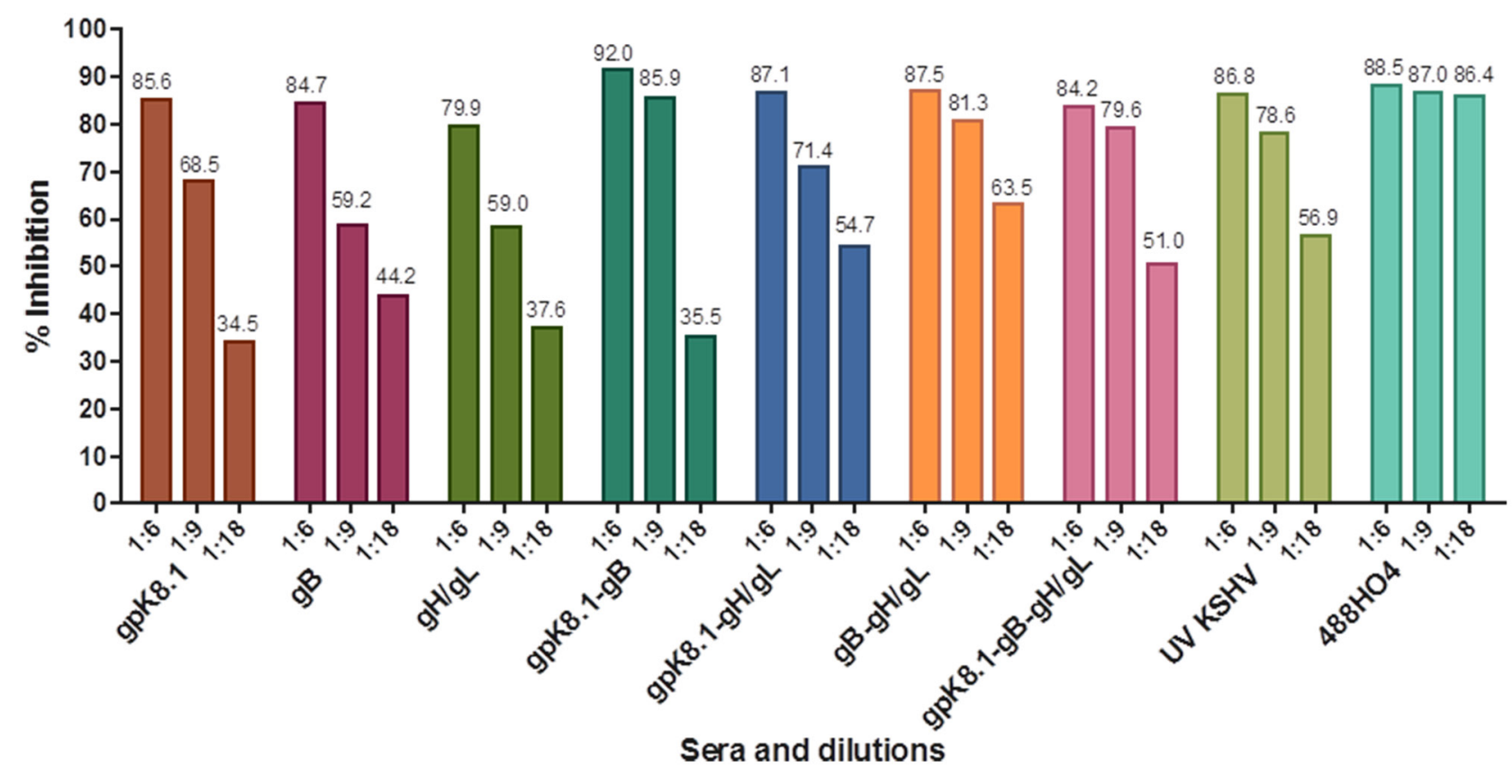

Figure 6: Neutralization assay of KSHV-eGFP with sera from mice immunized with KSHV VLPs. Pooled heat-inactivated terminal bleed sera from 5 animals per immunization treatment was pre-incubated with KSHV-eGFP purified from lytically induced iSLK. 219 cells, then incubated at $37^{\circ} \mathrm{C}$ for $2 \mathrm{~h}$ with HEK-293 cells. The virus/serum inoculum was removed and replaced with $10 \%$ DMEM, and the HEK-293 cells further incubated at $37^{\circ} \mathrm{C}$ for $48 \mathrm{~h}$. KSHV-eGFP+ cells, indicative of infection, were enumerated by flow cytometry. Known KSHV-positive plasma (488HO4; a gift of Dr. Wood University of Nebraska, Lincoln) and sera from UV-KSHV immunized mice served as positive controls Human sera 488HO4 neutralized $\sim 80 \%$ of KSHV infection at 1:6, 1:9, and 1:18 dilutions. Sera from mice immunized with TNE (not shown) served as negative control and was used to normalize the percent infection. All the groups of mice immunized with single VLPs or different combinations of VLPs generated a neutralizing antibody response against KSHV-eGFP. At a 1:18 serum dilution, pooled serum from individual mice immunized with a combination of either gpK8.1-gH/gL, gB-gH/gL, or gpK8.1$\mathrm{gB}-\mathrm{gH} / \mathrm{gL}$ VLPs showed the best neutralization, inhibiting infection by $54.7 \%, 63.5 \%$, and $51.0 \%$ respectively, compared to $<50 \%$ for the mice immunized with single gpK8.1, gB, or gH/gL VLPs. 
glycoprotein-based VLPs (gpK8.1-gB, gpK8.1-gH/gL, or gpK8.1-gB-gH/gL) induced a neutralizing antibody response that was comparable to that of UV-KSHV. This demonstrates the additive effect of combining more than one immunogen in a potential vaccine, and confirms that gpK8.1 is an important immunogen to include in the vaccine. We are currently developing a polyvalent VLP that expresses all four glycoproteins (gpK8.1, $\mathrm{gB}$, and the $\mathrm{gH} / \mathrm{gL}$ complex) on the surface of a single VLP. Multivalent VLPs are known to induce higher immunological responses than corresponding monovalent VLPs $[49,50]$. A single, multivalent VLP would also be more cost-effective to produce in large-scale.
All herpesviruses persist for life in infected individuals, which means that only complete eradication of the latent virus can cure infection. Thus, our ultimate goal is to develop a vaccine that elicits both humoral and cellular responses to limit viral infection and eradicate infected cells. To elicit a cellular immune response in addition to the humoral response, future KSHV glycoprotein-based VLPs should also incorporate intracellular KSHV T-cell antigens, such as latent nuclear antigen-1 (LANA1; ORF73). LANA1 is responsible for maintaining KSHV as an episome in infected cells, while the virus undergoes latent replication [51]. LANA1 is expressed in all KSHV-infected cells, including KS tumor

\section{Antibody-mediated inhibition of KSHV infection}

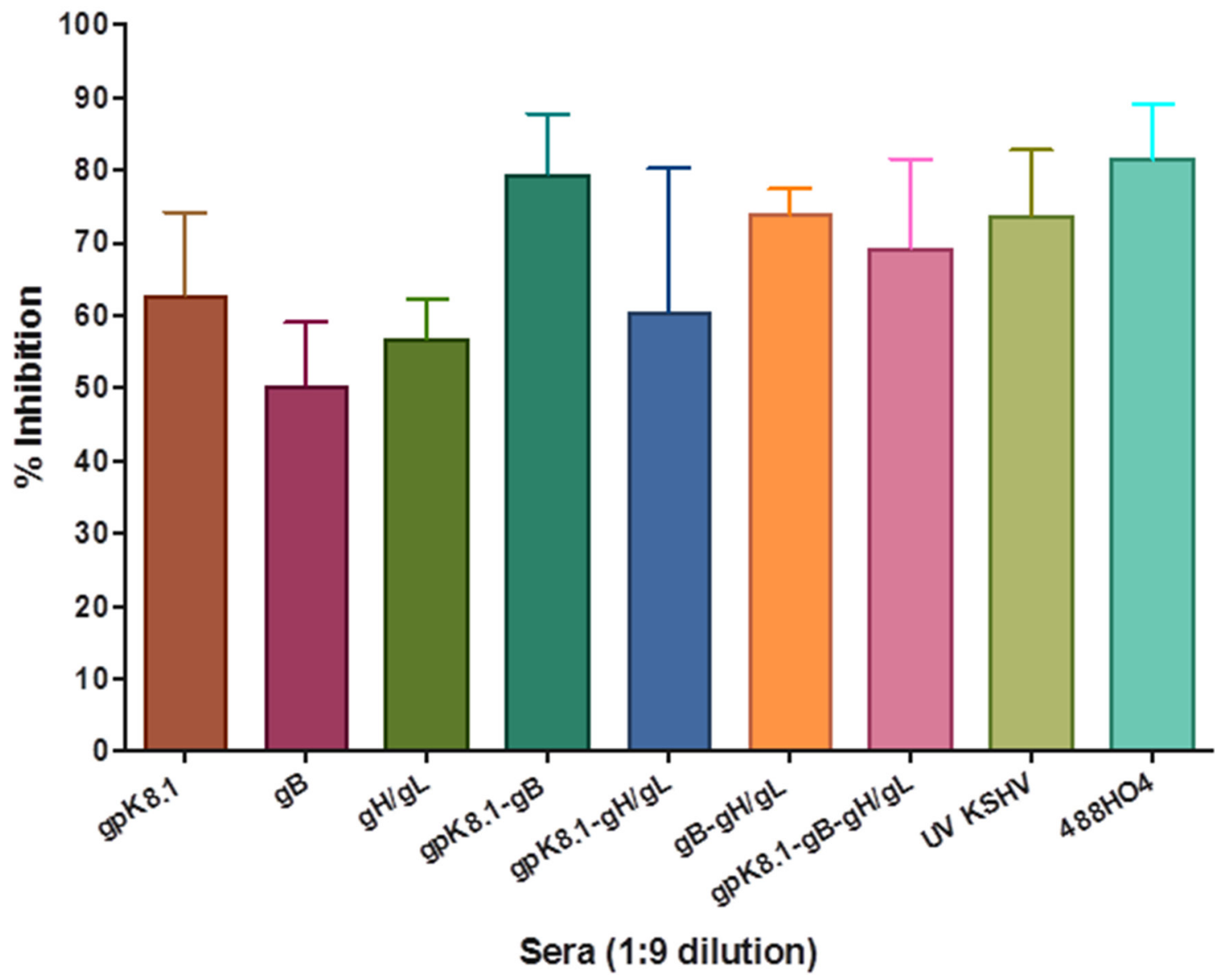

Figure 7: Neutralization assay of KSHV-eGFP+ with 1:9 diluted sera from mice immunized with KSHV VLPs. Neutralization assays were performed as described in Figure 6 and Materials and Methods. Data from three independent experiments at a 1:9 serum dilution is presented. The percent inhibition of infection is shown as the mean (top of bar) \pm the SEM (error bar above bar) for each serum group. Known KSHV positive plasma (488HO4) served as positive control and neutralized $>80 \%$ of KSHV infection. Serum from mice immunized with TNE (data not shown) served as negative control and was used to normalize the percent infection. As a single immunogen, gpK8.1 VLPs stimulated comparable neutralizing antibody activity to that of UV-inactivated KSHV (positive control). In contrast, UV-inactivated KSHV stimulated higher titers of neutralizing antibodies compared to $\mathrm{gB}(\mathrm{p}=0.0316)$ or $\mathrm{gH} / \mathrm{gL}(\mathrm{p}=0.0486)$. Mice immunized with the combination of $\mathrm{gB}$ and $\mathrm{gH} / \mathrm{gL}$ VLPs had a better neutralizing antibody response than those immunized with either $\mathrm{gB}$ $(\mathrm{p}=0.0268)$, or $\mathrm{gH} / \mathrm{gL}(\mathrm{p}=0.0397)$ VLPs as single immunogens. Immunization with all VLP combinations containing gpK8.1 (gpK8.1-gB, gpK8.1-gH/gL and gpK8.1-gB-gH/gL) stimulated comparable neutralizing antibody activity to UV-KSHV serum. 
cells, and is a target of the cellular immune response mediated by CD4+ and CD8+ T cells [52]. LANA1specific $\mathrm{T}$ cells are effective in controlling growth of KSHV-immortalized endothelial and B cells [53, 54]. Therefore, we expect that a VLP comprised of gpK8.1$\mathrm{gB}-\mathrm{gH} / \mathrm{gL}$ and LANA1 would elicit both humoral and cell-mediated immune responses in immunized hosts. This dual response would allow the VLP vaccine to provide both a prophylactic and therapeutic effect; thus, it could be used to both prevent and treat KSHV and KS in endemic areas. The inclusion of other latent KSHV proteins, such as v-Cyclin (ORF72), v-FLIP (K13 or ORF71), Kaposin (K12), and viral miRNAs, which are also constitutively expressed from the latency locus of the viral genome [55], should be considered as part of a polyvalent KSHV vaccine. A polyvalent vaccine incorporating multiple KSHV glycoproteins and latent proteins could allow tailored targeting of $\mathrm{KSHV}$-associated tumors as a therapeutic treatment strategy.

\section{Study limitations}

In vivo, KSHV typically infects epithelial, endothelial, and B cells [56]. Although we showed neutralization of infection in an epithelial cell model, due to limited amounts of mouse sera, we were unable to test the ability of the VLP-generated neutralizing antibodies to block virus infection in endothelial and B cells. Future studies could test this in primary cells or in cell lines susceptible to KSHV infection, such as MC116 [57].

\section{CONCLUSIONS}

We have generated the first KSHV subunit vaccines potentially capable of preventing $\mathrm{KSHV}$ infection in vivo and thus possibly capable of preventing KS. KS continues to be a major public health concern in subSaharan Africa, where KSHV is endemic, and large numbers of HIV-infected individuals have late or no access to HAART [58]. A recent review on the burden of cancer associated with infectious agents listed KS as the second largest cancer burden in sub-Saharan Africa, behind only cervical cancer [59]. The accuracy of clinical and histopathologic diagnosis of $\mathrm{KS}$ in low-resource settings such as sub-Saharan Africa is sub-optimal [60]; thus, prevention is the best way to limit KS morbidity and mortality. A prophylactic vaccine to prevent KSHV and $\mathrm{KS}$ is critical to reduce the burden of disease in these settings. In endemic areas, KSHV infection is acquired mainly through horizontal transmission, most likely during childhood [4, 48]. A comprehensive prospective study evaluating and comparing primary infection with multiple herpesviruses in a cohort of African infants beginning at birth showed that despite endemicity of KSHV in the region, no KSHV infection was observed in the first 18 months after birth [61]. Instead, other herpesviruses were acquired first. This evidence of delayed KSHV infection suggests that an 18-month window of opportunity exists, in which to vaccinate children and curb KSHV incidence and transmission. Furthermore, seroprevalence of KSHV is low in many developed countries; thus, an effective prophylactic vaccine will be an important tool in eradicating the rare cases of KS that occur during immunosuppression, especially in organ transplant or AIDS patients.

\section{MATERIALS AND METHODS}

\section{Ethics statement}

Animal procedures were performed in accordance with the University of Massachusetts Medical School (UMMS) Institutional Animal Care and Use Committee and Institutional Biosafety Committee.

\section{Cell lines and virus}

Chinese hamster ovary (CHO), human embryonic kidney (HEK-293), East Lansing Line 0 (ELL-0), and human mast (HMC-1) cell lines were purchased from the American Type Culture Collection (ATCC). Parent iSLK and iSLK.219 cells harboring KSHV expressing a reporter gene, enhanced green fluorescence protein, (eGFP), from the human elongation factor (EF)-1 $\alpha$ promoter [62] were obtained from Dr. D. Dittmer of University of North Carolina, Chapel Hill, NC. CHO, HEK-293, and ELL-0 cell lines were cultured in Dulbecco's Modified Eagle's Medium (DMEM). HMC-1 cell line was cultured in Iscove's Modified Dulbecco's Medium. All cell culture media contained $10 \%$ heat-inactivated fetal bovine serum (FBS), 2\% penicillin-streptomycin, and 1\% L-glutamine. Media for culturing iSLK.219 cells was supplemented with neomycin $(250 \mu \mathrm{g} / \mathrm{mL})$, hygromycin $(400 \mu \mathrm{g} / \mathrm{mL})$, and puromycin $(10 \mu \mathrm{g} / \mathrm{mL})$ to maintain stable selection of both recombinant KSHV-eGFP and the RTA gene under the pRetro-X Tet-ON inducible system.

Lytic induction of KSHV-eGFP expression in iSLK. 219 cells and KSHV-eGFP virus purification were performed as previously described [62]. Purified NDV B1 strain (lysate) was a gift of Dr. T. Morrison (UMMS, Worcester).

\section{Antibodies and cholera toxin B}

Primary mouse monoclonal $\mathrm{IgG}_{2 \mathrm{a}}$ anti-gpK8.1 (clone 4A4), which detects the ectodomain of the protein was purchased from Santa Cruz. Rabbit polyclonal anti-NDV and anti-NDV F HR2 have been described and were gifts of T. Morrison of UMMS, Worcester, MA [63]. Rabbit polyclonal anti-NDV F-tail was raised against a synthetic peptide (YKQKAQQKTLLWLGNN) with the sequence of the cytoplasmic domain of the fusion protein, (amino 
acids 527 to 543) and purified by Thermo Scientific. Rabbit polyclonal anti-gB and anti-gH used in HMC-1 cell binding experiments were gifts of Dr. B. Chandran of Rosalind Franklin University, Chicago, IL. KSHV-positive human plasma (488HO4) was obtained from Dr. C. Wood, University of Nebraska-Lincoln, NE [48]. Secondary antibodies horseradish peroxidase (HRP)-conjugated goat anti-mouse IgG and goat anti-rabbit IgG antibodies for immunoblot and ELISA were purchased from Sigma. Goat Fab-2 anti-mouse IgG $(\mathrm{H}+\mathrm{L})$ conjugated to AF488 or AF594, used for cytometric and fluorescence microscopy analyses, and molecular probe cholera toxin B conjugated with AF488, for staining lipid rafts, were all purchased from Thermo Scientific.

\section{Plasmid vectors}

Individual chimeric fragments consisting of amino acids (aa) 1-197, 1-736, and 1-702 encoding the gpK8.1, gB, and gH ectodomains, respectively, were constructed and fused to the NDV-F heptad repeat (HR2), transmembrane (TM), and cytoplasmic (CT) domains (aa 466-553). A fragment encoding the TM and CT domains of the NDV-HN protein (aa 1-48) was fused to the ectodomain of gL (aa 29-167). The chimeric cDNAs were synthesized by Genewiz, Boston, MA, and individually cloned into the pCAGGS mammalian expression vector [64] to generate pCAGGS-KSHV gpK8.1-F, pCAGGSKSHV gB-F, pCAGGS-KSHV gH-F, and pCAGGSKSHV gL-HN. Full-length gpK8.1 wild-type (WT) (aa 1-228), gB WT (aa 1-845), gH WT (aa 1-730), and gL WT (aa 1-167) were also synthesized and individually cloned into pCAGGS vector for use in control experiments. pCAGGS-F, pCAGGS-M, and pCAGGS-NP derived from NDV have been described [38]. All the cloned cDNAs were sequenced to confirm their fidelity.

\section{gpK8.1 transfection and flow cytometry analyses}

To determine surface expression of both wild-type and chimeric KSHV gpK8.1 envelope glycoprotein, 80\% sub-confluent $\mathrm{CHO}$ cells seeded in six-well tissue culture plates were transfected with $1 \mu \mathrm{g} /$ well of pCAGGS, pCAGGS-KSHV gpK8.1 full-length (WT), or pCAGGSKSHV gpK8.1-F using Mirus reagent (Mirus Bio LLC), according to the manufacturer's instructions. Cells were harvested $48 \mathrm{~h}$ post-transfection, washed twice by centrifugation at 335 rcf for $5 \mathrm{~min}$, and re-suspended in PBS. The cells were incubated with anti-gpK8.1 mAb for $10 \mathrm{~min}$ at room temperature, washed twice, re-incubated with goat anti-mouse AF488, and washed thrice.

Cytometric analysis for gpK8.1 protein surface expression was performed on an LSRII benchtop FC (Becton-Dickinson, BD) and data was analyzed using Flow Jo Cytometry Analysis software (Tree Star Inc) as previously described [25]. A minimum of 10,000 events was recorded for each analysis. Experiments were repeated at least thrice and representative data is presented. Cell surface expression of gB-F, gB-WT, gH-F, gH-WT, gL$\mathrm{HN}$, gL-WT, or gH-F/gL-HN were not determined by flow cytometry due to lack of primary monoclonal antibodies for staining transfected cells.

\section{Generation and purification of VLPs}

For VLP preparation, equal amounts ( $8 \mu \mathrm{g} /$ plasmid $)$ of pCAGGS-NDV-M, -NP, and either pCAGGS-KSHV gpK8.1-F, -gB-F, or -gH-F and -gL-HN (for KSHV gpK8.1, gB, and gH/gL VLPs, respectively) were cotransfected into CHO cells seeded in $\mathrm{T}-175 \mathrm{~cm}^{2}$ flasks, using Mirus reagent, as previously described [25]. Forty flasks were seeded for each VLP preparation. Supernatant containing VLPs was collected between 24 to $96 \mathrm{~h}$ posttransfection. VLPs were isolated by sedimentation and sucrose gradient purification, as previously described [36].

\section{Silver stain and immunoblot}

To detect the incorporation of proteins into VLPs, purified KSHV glycoprotein-based VLPs, untransfected CHO cells (negative control), and cells transfected with the respective wild-type proteins (positive controls) were first lysed in RIPA buffer (Boston Bioproducts). Lysates were incubated on ice for $30 \mathrm{~min}$, with vortexing every $10 \mathrm{~min}$, then centrifuged for $10 \mathrm{~min}$ at $18,407 \mathrm{rcf}$ in a microcentrifuge. The protein content of each lysate was determined by Bradford assay (Sigma). Lysates were boiled for $5 \mathrm{~min}$ in lithium dodecyl sulphate sample buffer (Thermo Scientific) under reducing and non-reducing conditions. A known quantity of protein lysate was loaded onto a 4-12\% polyacrylamide gel for protein separation using $1 \mathrm{X}$ MES SDS running buffer (Life Sciences Technologies). Immunoblot analyses for respective proteins (gpK8.1, gB, gH/gL, NDV-NP, and -M) were performed by transferring proteins from the gel to a polyvinylidene fluoride membrane using iBlot (Life Sciences Tech). Membranes were blocked with 3\% bovine serum albumin (Sigma) in Tris-buffered saline (TBS) for $45 \mathrm{~min}$ and proteins were detected with specific primary and secondary antibodies as previously described $[65,66]$. Protein bands were also detected by Pierce's silver stain kit according to the manufacturer's recommendation.

\section{Cell binding assays and electron microscopy}

VLPs and viruses were analyzed by electron microscopy as described [67]. For cell binding assays, 5 $\mu \mathrm{l}$ of KSHV glycoprotein-based purified VLPs (gpK8.1, $\mathrm{gB}$, or $\mathrm{gH} / \mathrm{gL}$ ) were incubated with $\mathrm{HMC}-1$ cells for $10 \mathrm{~min}$ at room temperature and detected with antigpK8.1 mAb, polyclonal anti-gB, or polyclonal anti$\mathrm{gH}$. Lipid rafts in the cell membranes were stained with cholera toxin (cell membrane tracker) and nuclei were stained with 4',6-diamidino-2-phenylindole (DAPI). For 
electron microscopy, purified VLPs were dialyzed against $1 \mathrm{~L}$ of TNE buffer (100 mM Tris; $2.0 \mathrm{M} \mathrm{NaCl} ; 10 \mathrm{mM}$ EDTA; pH 7.4) to remove residual sucrose, incubated with 3\% bovine serum albumin (BSA) in TNE for 45 min, and embedded on a grid. $5 \mu 1$ of the virus/VLP at 1:40 dilution was individually added to the grid for $1 \mathrm{~h}$ at room temperature. After two final washes, the grids were negatively stained with $12 \%$ phosphotungstic acid ( $\mathrm{pH} 7)$ for $15 \mathrm{sec}$, air dried for $30 \mathrm{~min}$, and examined using a Tecnai transmission electron microscope (FEI).

\section{Immunization}

Nine groups of five 6-8-week-old female BALB/c mice (Jackson Laboratories) each were immunized intraperitoneally with $10 \mu \mathrm{g}$ of either purified KSHV gpK8.1 VLP, gB VLP, gH/gL VLP, or combinations of gpK8.1 and $\mathrm{gB}, \mathrm{gpK} 8.1$ and $\mathrm{gH} / \mathrm{gL}, \mathrm{gB}$ and $\mathrm{gH} / \mathrm{gL}$, or gpK8.1 and $\mathrm{gB}$ and $\mathrm{gH} / \mathrm{gL}$ VLPs in $0.5 \mathrm{~mL}$ TNE buffer containing $10 \%$ sucrose without any adjuvant. UV-inactivated KSHV-eGFP purified from lytically induced iSLK.219 cells (10 $\mu \mathrm{g}$ in 0.5 $\mathrm{mL}$ TNE) or TNE buffer alone $(0.5 \mathrm{~mL})$ served as positive and negative controls, respectively. UV-inactivation of KSHV was achieved by exposure to $254 \mathrm{~nm}$ UV light for 5 min (source model UVG-11, UVP) from a distance of $10 \mathrm{~cm}$, producing complete loss of eGFP expression upon KSHV infection of 293T cells.

Mice were boosted with $10 \mu \mathrm{g}$ of each antigen on Days 29 and 54. After primary immunization, tail vein blood was obtained at Days 14, 46, and 84. A terminal bleed was obtained on Days 133. All time points were used to determine anti-KSHV glycoprotein IgG response.

\section{Enzyme-linked immunosorbent assay (ELISA) to determine sera antibody titer}

Anti-KSHV IgG absorbance was measured by ELISA using cell lysate from iSLK.219 cells stimulated to induce lytic expression of KSHV-eGFP proteins as a target antigen. Lysates from iSLK cells (free of KSHV infection) and irrelevant ELL-0 cell lines were used as negative controls. Briefly, 96-well microtiter plates (Costar) were coated overnight with $8 \mu \mathrm{g} / \mathrm{mL}$ per well of lytically induced iSLK.219 KSHV-eGFP-expressing cell lysate in PBS at $4{ }^{\circ} \mathrm{C}$, then blocked with $2 \% \mathrm{BSA}$ at room temperature. Serum samples diluted 1:100, 1:300, 1:900, and 1:2700 in PBS were added, incubated for $2 \mathrm{~h}$ at room temperature, then washed thrice. Antibody binding was detected with HRP-labeled goat anti-mouse IgG secondary antibody incubated at room temperature for an hour. Plates were washed five times and the substrate ABTS (KPL) was added. Reactions were stopped with ABTS peroxidase stop solution (KPL). Optical density (OD) was read at $450 \mathrm{~nm}$ with an ELISA reader (FilterMax F3) and corrected for background. The absorbance resulting from serum antibody binding to KSHV-eGFP-expressing iSLK.219 cell lysate target antigen is shown as summary data for each group of mice. Absorbance data at 1:100 are provided as the mean (top of bar) \pm the SEM (error bar above bar) for five mice per group. KSHV VLPs induced increasing titers of antiKSHV specific IgG antibodies after each immunization.

\section{KSHV neutralization studies}

Terminal bleed sera from each group of immunized mice were pooled and incubated at $56^{\circ} \mathrm{C}$ for $30 \mathrm{~min}$ to heat-inactivate serum complement. The virus titer for the in vitro neutralization assays was determined as described [25]. Briefly, different concentrations of a frozen stock of KSHV-eGFP purified from lytically induced iSLK.219 cells were incubated with HEK-293 cells seeded overnight in 48-well plates, in the absence of serum. Flow cytometry was used to detect fluorescence, indicative of infection. After infection with $30 \mu \mathrm{l}$ of stock KSHV-eGFP, $\sim 15 \%$ (1,500 cells) of total seeded HEK-293 cells reproducibly fluoresced upon detection by flow cytometry. For effective flow cytometry reading, the number of HEK-293 cells was increased and seeded in 24-well plates and the amount of virus used for infection was doubled to $60 \mu \mathrm{l}$ to accommodate the increase in cell population.

Serial two-fold dilutions of heat-inactivated sera were prepared in Dulbecco's modified Eagle's medium (DMEM) without fetal bovine serum to a volume of $60 \mu \mathrm{l}$. This serum was incubated with $60 \mu \mathrm{KSHV}$-eGFP for $2 \mathrm{~h}$ at $37^{\circ} \mathrm{C}$. The serum/virus mixture was topped up with serumfree media to a final volume of $200 \mu \mathrm{l}$, yielding dilutions ranging from 1:3 to 1:150, then used to infect HEK-293 cells that had been seeded at $60-80 \%$ confluence in 24 well plates the night before. The KSHV-eGFP-incubated sera were cultured with the cells for $2 \mathrm{~h}$ at $37^{\circ} \mathrm{C}$. Known neutralizing KSHV-positive plasma (488HO4) [48] and serum from TNE only-treated mice served as positive and negative controls, respectively. The virus/serum inoculum was removed and replaced with $500 \mu 1$ of fresh DMEM plus $10 \%$ FBS. Plates were incubated for $48 \mathrm{~h}$ at $37^{\circ} \mathrm{C}$ and the number of eGFP-positive cells was determined by flow cytometry. Neutralization assays were performed in triplicate to determine the optimal serum dilutions for the assays. Evaluation of data to determine the magnitude of neutralization was performed as previously described, and quantified as percent inhibition of viral infection [48]. Briefly, sample data was first normalized to input viral infection and calculated as: Normalized Percent Infectivity $=$ (Sample percent infectivity/Virus-only percent infectivity) $\mathrm{x} 100$. The percent inhibition of viral infection was then calculated as: (100 - Normalized Percent Infectivity).

\section{Statistical analysis}

Graph Pad Prism 6 Software was used for statistical analyses of data. The differences between the percent inhibition of infection between the immunized and control 
groups of mice were analyzed using unpaired two-tailed t-tests for independent groups. Statistical significance of the tests was based on a p-value equal to or lower than 0.05 .

\section{Authors' contributions}

Conceived and designed experiments: JGO, AKB. Performed experiments: JGO, AKB, MP, TT, GTA, PY. Analyzed the data: JGO, AKB, MP, TT, GTA, PY. Contributed reagents/materials/analysis tools: JGO. Wrote the manuscript: AKB, JGO, MP, TT, GTA, PY. Obtained permission for use of cell lines and animals: JGO.

\section{ACKNOWLEDGMENTS}

This work was supported by the National Institutes of Health K01 CA184388-02 to JGO and by the American Cancer Society International Fellowships to AKB. We thank Dr. Robert W. Finberg and the Department of Medicine, University of Massachusetts Medical School, for providing reagents and partial funding support for this study. The funding agencies had no role in study design, data collection and data analysis, preparation of the manuscript, or decision to publish. We thank Dr. Sarah T. Wilkinson for editing of the manuscript and for her insightful feedback and discussion.

\section{COMPETING INTERESTS} interests.

The Authors declare that they have no competing

\section{REFERENCES}

1. Chang Y, Cesarman E, Pessin MS, Lee F, Culpepper J, Knowles DM, Moore PS. Identification of herpesviruslike DNA sequences in AIDS-associated Kaposi's sarcoma. Science. 1994; 266:1865-1869.

2. Sousa-Squiavinato AC, Silvestre RN, Elgui De Oliveira D. Biology and oncogenicity of the Kaposi sarcoma herpesvirus K1 protein. Rev Med Virol. 2015; 25:273-285.

3. Brayfield BP, Kankasa C, West JT, Muyanga J, Bhat G, Klaskala W, Mitchell CD, Wood C. Distribution of Kaposi Sarcoma_Associated Herpesvirus/Human Herpesvirus 8 in Maternal Saliva and Breast Milk in Zambia: Implications for Transmission. J Infect Dis. 2004; 189:2260-2270.

4. Butler LM, Were WA, Balinandi S, Downing R, Dollard S, Neilands TB, Gupta S, Rutherford GW, Mermin J. Human herpesvirus 8 infection in children and adults in a population-based study in rural Uganda. J Infect Dis. 2011; 203:625-634
5. Johnston C, Orem J, Okuku F, Kalinaki M, Saracino M, Katongole-Mbidde E, Sande M, Ronald A, McAdam K, Huang ML, Drolette L, Selke S, Wald A, et al. Impact of HIV infection and Kaposi sarcoma on human herpesvirus-8 mucosal replication and dissemination in Uganda. PLoS One. 2009; 4:e4222.

6. Mbulaiteye SM, Pfeiffer RM, Engels EA, Marshall V, Bakaki PM, Owor AM, Ndugwa CM, Katongole-Mbidde E, Goedert JJ, Biggar RJ, Whitby D. Detection of Kaposi Sarcoma-Associaed Herpesvirus DNA in Saliva and BuffyCoat Samples from Children with Sickle Cell Disease in Uganda. The Journal of Infectious Diseases. 2004; 190:1382-1386.

7. Pauk J, Huang ML, Brodie SJ, Wald A, Koelle DM, Schacker T, Celum C, Selek S, Corey L. Mucosal Shedding of Human Herpesvirus 8 in Men. The New England Journal of Medicine. 2000; 343:1369-1377.

8. Martin JN, Ganem DE, Osmond DH, Page-Shafer KA, Macrae D, Kedes DH. Sexual Transmission and the Natural History of Human Herpesvirus 8 Infection. The New England Journal of Medicine. 1998; 338:948-954.

9. Barozzi P, Luppi M, Facchetti F, Mecucci C, Alu M, Sarid R, Rasini V, Ravazzini L, Rossi E, Festa S, Crescenzi B, Wolf DG, Schulz TF, et al. Post-transplant Kaposi sarcoma originates from the seeding of donor-derived progenitors. Nat Med. 2003; 9:554-561.

10. Dedicoat M, Newton R. Review of the distribution of Kaposi's sarcoma-associated herpesvirus (KSHV) in Africa in relation to the incidence of Kaposi's sarcoma. Br J Cancer. 2003; 88:1-3.

11. Gao SJ, Kingsley L, Li M, Zheng W, Parravicini C, Ziegler J, Newton R, Rinaldo CR, Saah A, Phair J, Detels R, Chang Y, Moore PS. KSHV antibodies among Americans, Italians and Ugandans with and without Kaposi's sarcoma. Nat Med. 1996; 2:925-928.

12. Simpson GR, Schulz TF, Whitby D, Cook PM, Boshoff C, Rainbow L, Howard MR, Gao SJ, Bohenzky RA, Simmonds P, Lee C, de Ruiter A, Hatzakis A, et al. Prevalence of Kaposi's sarcoma associated herpesvirus infection measured by antibodies to recombinant capsid protein and latent immunofluorescence antigen. The Lancet. 1996; 348:1133-1138.

13. Whitby D, Luppi M, Barozzi P, Boshoff C, Weiss RA, Torelli G. Human Herpesvirus 8 Seroprevalence in Blood Donors and Lymphoma Patients from Different Regions of Italy. J Natl Cancer Inst. 1998; 90:395-397.

14. Bhutani M, Polizzotto MN, Uldrick TS, Yarchoan R. Kaposi sarcoma-associated herpesvirus-associated malignancies: epidemiology, pathogenesis and advances in treatment. Semin Oncol. 2015; 42:223-246.

15. Bouvard V, Baan R, Grosse Y, Secretan B, El Ghissassi F, Benbrahim-Tallaa L, Guha N, Freeman C, Galichet L, Coglian V, Group WIAfRoCMW. A review of human carcinogens - Part B: biological agents. The Lancet Oncology. 2009; 10:321-322. 
16. Parkin DM. The global health burden of infectionassociated cancers in the year 2002. Int J Cancer. 2006; 118:3030-3044.

17. Rohner E, Valeri F, Maskew M, Prozesky H, Rabie H, Garone D, Dickinson D, Chimbetete C, Lumano-Mulenga P, Sikazwe I, Wyss N, Clough-Gorr KM, Egger M, et al. Incidence rate of Kaposi sarcoma in HIV-infected patients on antiretroviral therapy in Southern Africa: a prospective multicohort study. J Acquir Immune Defic Syndr. 2014; 67:547-554

18. Casper C. The increasing burden of HIV-associated malignancies in resource-limited regions. Annu Rev Med. 2011; 62:157-170.

19. Mbulaiteye SM, Katabira ET, Wabinga H, Parkin DM, Virgo P, Ochai R, Workneh M, Coutinho A, Engels EA. Spectrum of cancers among HIV-infected persons in Africa: the Uganda AIDS-Cancer Registry Match Study. Int J Cancer. 2006; 118:985-990.

20. Wabinga HR, Parkin DM, Wabwire-Mange F, Nambooze S. Trends in cancer incidence in Kyadondo County, Uganda, 1960-1997. Brotish Journal of Cancer. 2000; 82:1585-1592.

21. Feller L KRA, Gugushe TS, Chikte UM, Wood NH, Meyerov R, Lemmer J. HIV-associated Kaposi sarcoma in African children. SADJ. 2010; 65:20-22.

22. Torre LA, Bray F, Siegel RL, Ferlay J, Lortet-Tieulent, Jemal A. Global cancer statistics, 2012. CA Cancer J Clin. 2015; 65:87-108.

23. Nguyen HQ, Magaret AS, Kitahata MM, Van Rompaey SE, Wald A,Casper C. Persistent Kaposi sarcoma in the era of highly active antiretroviral therapy: characterizing the predictors of clinical response. AIDS. 2008; 22:937-945.

24. Wussow F, Chiuppesi F, Martinez J, Campo J, Johnson E, Flechsig C, Newell M, Tran E, Ortiz J, La Rosa C, Herrmann A, Longmate J, Chakraborty R, et al. Human cytomegalovirus vaccine based on the envelope $\mathrm{gH} / \mathrm{gL}$ pentamer complex. PLoS Pathog. 2014; 10:e1004524.

25. Ogembo JG, Muraswki MR, McGinnes LW, Parcharidou A, Sutiwisesak R, Tison T, Avendano J, Agnani D, Finberg RW, Morrison TG, Fingeroth JD. A chimeric EBV gp350/220-based VLP replicates the virion B-cell attachment mechanism and elicits long-lasting neutralizing antibodies in mice. J Transl Med. 2015; 13:50.

26. Wu TTQ, Ang J, Sun R. Vaccine prospect of Kaposi sarcoma-associated herpesvirus. Curr Opin Virol. 2012; 2:482-488.

27. Spear PG LR. Herpesvirus entry: An update. J Virol. 2003; 77:10179-10185.

28. Heldwein EE KC. Entry of herpesviruses into mammalian cells. Cells Mol Life Sci. 2008; 65:1653-1668.

29. Akula SM, Pramod NP, Wang FZ, Chandran B. Human herpesvirus 8 envelope-associated glycoprotein B interacts with heparan sulfate-like moieties. Virology. 2001; 284:235-249.
30. Luna RE ZF, Baghlan A, Chouljenko V, Forghani B, Gao SJ, Kousoulas KG. Kaposi's sarcoma-associated herpesvirus glycoprotein K8.1 is dispensable for virus entry. J Virol. 2004; 78:6389-6398.

31. Chandran B. Early events in Kaposi's sarcoma-associated herpesvirus infection of target cells. J Virol. 2010; 84:2188-2199.

32. Veettil MV, Bandyopadhyay C, Dutta D, Chandran B. Interaction of KSHV with host cell surface receptors and cell entry. Viruses. 2014; 6:4024-4046.

33. Hahn A, Birkmann A, Wies E, Dorer D, Mahr K, Sturzl M, Titgemeyer F, Neipel F. Kaposi's sarcoma-associated herpesvirus $\mathrm{gH} / \mathrm{gL}$ : glycoprotein export and interaction with cellular receptors. J Virol. 2009; 83:396-407.

34. Morrison TG. Protein conformation in a vaccine matters. Oncotarget. 2015; 6:21781-21782. doi: 10.18632/ oncotarget.5102.

35. Kushnir N, Streatfield SJ, Yusibov V. Virus-like particles as a highly efficient vaccine platform: diversity of targets and production systems and advances in clinical development. Vaccine. 2012; 31:58-83.

36. McGinnes LW, Morrison TG. Newcastle disease viruslike particles: preparation, purification, quantification, and incorporation of foreign glycoproteins. Curr Protoc Microbiol. 2013; 30:Unit 1812.

37. Baghian A, Luftig M, Black JB, Meng YX, Pau CP, Voss T, Pellett PE, Kousoulas KG. Glycoprotein B of human herpesvirus 8 is a component of the virion in a cleaved form composed of amino- and carboxyl-terminal fragments. Virology. 2000; 269:18-25.

38. Pantua HD, McGinnes LW, Peeples ME, Morrison TG. Requirements for the assembly and release of Newcastle disease virus-like particles. J Virol. 2006; 80:11062-11073.

39. Crevar CJ, Ross TM. Elicitation of protective immune responses using a bivalent H5N1 VLP vaccine. Virol J. 2008; 5:131.

40. Bechtel JT, Liang Y, Hvidding J, Ganem D. Host range of Kaposi's sarcoma-associated herpesvirus in cultured cells. J Virol. 2003; 77:6474-6481.

41. Wang LX, Kang G, Kumar P, Lu W, Li Y, Zhou Y, Li Q, Wood C. Humanized-BLT mouse model of Kaposi's sarcoma-associated herpesvirus infection. Proc Natl Acad Sci U S A. 2014; 111:3146-3151.

42. Chang H, Wachtman LM, Pearson CB, Lee JS, Lee HR, Lee SH, Vieira J, Mansfield KG, Jung JU. Non-human primate model of Kaposi's sarcoma-associated herpesvirus infection. PLoS Pathog. 2009; 5:e1000606.

43. Caulfield MJ, Shi L, Wang S, Wang B, Tobery TW, Mach H, Ahl PL, Cannon JL, Cook JC, Heinrichs JH, Sitrin RD. Effect of Alternative Aluminium Adjuvants on the Absorption and Immunogenicity of HPV 16 L1 VLPs in Mice. Human Vaccines. 2007; 3:139-145.

44. Murawski MR, McGinnes LW, Finberg RW, Kurt-Jones EA, Massare MJ, Smith G, Heaton PM, Fraire AE, Morrison 
TG. Newcastle disease virus-like particles containing respiratory syncytial virus $\mathrm{G}$ protein induced protection in BALB/c mice, with no evidence of immunopathology. J Virol. 2010; 84:1110-1123.

45. Arnou R, Fiquet A, Thomas S, Sadorge C. Immunogenicity and safety of ZOSTAVAX ${ }^{\circledR}$ approaching expiry potency in individuals aged $\geq 50$ years. Human vaccines. 2011; 7:1060-1065.

46. Schleiss MR. Cytomegalovirus vaccines under clinical development. J Virus Erad. 2016; 2:198-207.

47. Sokal EM, Hoppenbrouwers K, Vandermeulen C, Moutschen M, Leonard P, Moreels A, Haumont M, Bollen A, Smets F, Denis M. Recombinant gp350 vaccine for infectious mononucleosis: a phase 2, randomized, double-blind, placebo-controlled trial to evaluate the safety, immunogenicity, and efficacy of an Epstein-Barr virus vaccine in healthy young adults. J Infect Dis. 2007; 196:1749-1753.

48. Kumar P, Kuwa NY, Minhas V, Marimo C, Shea DM, Kankasa C, Wood C. Higher levels of neutralizing antibodies against $\mathrm{KSHV}$ in $\mathrm{KS}$ patients compared to asymptomatic individuals from Zambia. PLoS One. 2013; 8:e71254.

49. Sominskaya I, Skrastina D, Dislers A, Vasiljev D, Mihailova M, Ose V, Dreilina D, Pumpens P. Construction and Immunological Evaluation of Mutlivalent Hepatitis B Virus (HBV) Core Virus-Like Particles Carrying HBV and HCV Epitopes. Clinical and Vaccine Immunology. 2010; 17:1027-1033.

50. Tyler M, Tumban E, Peabody DS, Chackerian B. The use of hybrid Virus-like Particles to enhance the immunogenicity of a broadly protective HPV vaccine. Biotechnol Bioeng. 2014; 111:2398-2406.

51. Collins CM, Medveczky PG. Genetic requirements for the episomal maintenance of oncogenic herpesvirus genomes. Adv Cancer Res. 2002; 84:155-174.

52. Nicol SM, Sabbah S, Brulois KF, Jung JU, Bell AI, Hislop AD. Primary B lymphocytes infected with KSHV can be expanded in vitro and are recognized by LANA-specific CD4+ T cells. J Virol. 2016.

53. Guihot A, Dupin N, Marcelin AG, Gorin I, Bedin AS, Bossi P, Galicier L, Oksenhendler E, Autran B, Carcelain G. Low $\mathrm{T}$ cell responses to human herpesvirus 8 in patients with AIDS-related and classic Kaposi sarcoma. The Journal of Infectious Diseases. 2006; 194:1078-1088.

54. Sabbah S, Jagne YJ, Zuo J, de Silva T, Ahasan MM, Brander C, Rowland-Jones S, Flanagan KL, Hislop AD. T-cell immunity to Kaposi sarcom-associated herpesvirus: recognition of primary effusion lymphoma by LANAspecific CD4+ T cells. Blood. 2012; 119:2083-2092.

55. Dittmer D, Lagunoff M, Renne R, Staskus K, Haase A, Ganem D. A cluster of latently expressed genes in Kaposi's sarcoma-associated herpesvirus. J Virol. 1998; 72:8309-8315.
56. Dupin N, Fisher C, Kellam P, Ariad S, Tulliez M, Franck N, van Marck E, Salmon D, Gorin I, Escande JP, Weiss RA, Alitalo K, Boshoff C. Distribution of human herpesvirus-8 latently infected cells in Kaposi's sarcoma, multicentric Castleman's disease, and primary effusion lymphoma. Proc Natl Acad Sci U S A. 1999; 96:4546-4551.

57. Dollery SJ, Santiago-Crespo RJ, Kardava L, Moir S, Berger EA. Efficient infection of a human B cell line with cellfree Kaposi's sarcoma-associated herpesvirus. J Virol. 2014; 88:1748-1757.

58. Robey RC, Bower M. Facing up to the ongoing challenge of Kaposi's sarcoma. Curr Opin Infect Dis. 2015; 28:31-40.

59. Plummer M, de Martel C, Vignat J, Ferlay J, Bray F, Franceschi S. Global burden of cancers attributable to infections in 2012: a synthetic analysis. The Lancet Global Health. 2016; 4:e609-e616.

60. Amerson E, Woodruff CM, Forrestel A, Wenger M, McCalmont T, LeBoit P, Maurer T, Laker-Oketta M, Muyindike W, Bwana M, Buziba N, Busakhala N, WoolsKaloustian K, et al. Accuracy of Clinical Suspicion and Pathologic Diagnosis of Kaposi Sarcoma in East Africa. J Acquir Immune Defic Syndr. 2016; 71:295-301.

61. Gantt S, Orem J, Krantz EM, Morrow RA, Selke S, Huang ML, Schiffer JT, Jerome KR, Nakaganda A, Wald A. Prospective characterization of the risk factors for transmission and symptoms of primary human herpesvirus infections among Ugandan infants. J Infect Dis. 2016:jiw076.

62. Myoung J, Ganem D. Generation of a doxycyclineinducible KSHV producer cell line of endothelial origin: maintenance of tight latency with efficient reactivation upon induction. J Virol Methods. 2011; 174:12-21.

63. McGinnes LW, Reitter JN, Gravel K, Morrison TG. Evidence for Mixed Membrane Topology of the Newcastle Disease Virus Fusion Protein. J Virol. 2003; 77:1951-1963.

64. Miyazaki J, Takaki S, Araki K, Tashiro F, Tominaga A, Takatsu K, Yamamura K. Expression vector system based on the chicken beta-actin promoter directs efficient production of interleukin-5. Gene. 1989; 79:269-277.

65. Laliberte JP, McGinnes LW, Peeples ME, Morrison TG. Integrity of membrane lipid rafts is necessary for the ordered assembly and release of infectious Newcastle disease virus particles. J Virol. 2006; 80:10652-10662.

66. Ogembo JG, Kannan L, Ghiran I, Nicholson-Weller A, Finberg RW, Tsokos GC, Fingeroth JD. Human complement receptor type 1/CD35 is an Epstein-Barr Virus receptor. Cell Rep. 2013; 3:371-385.

67. Battisti AJ, Meng G, Winkler DC, McGinnes LW, Plevka P, Steven AC, Morrison TG, Rossmann MG. Structure and assembly of a paramyxovirus matrix protein. Proc Natl Acad Sci U S A. 2012; 109:13996-14000. 